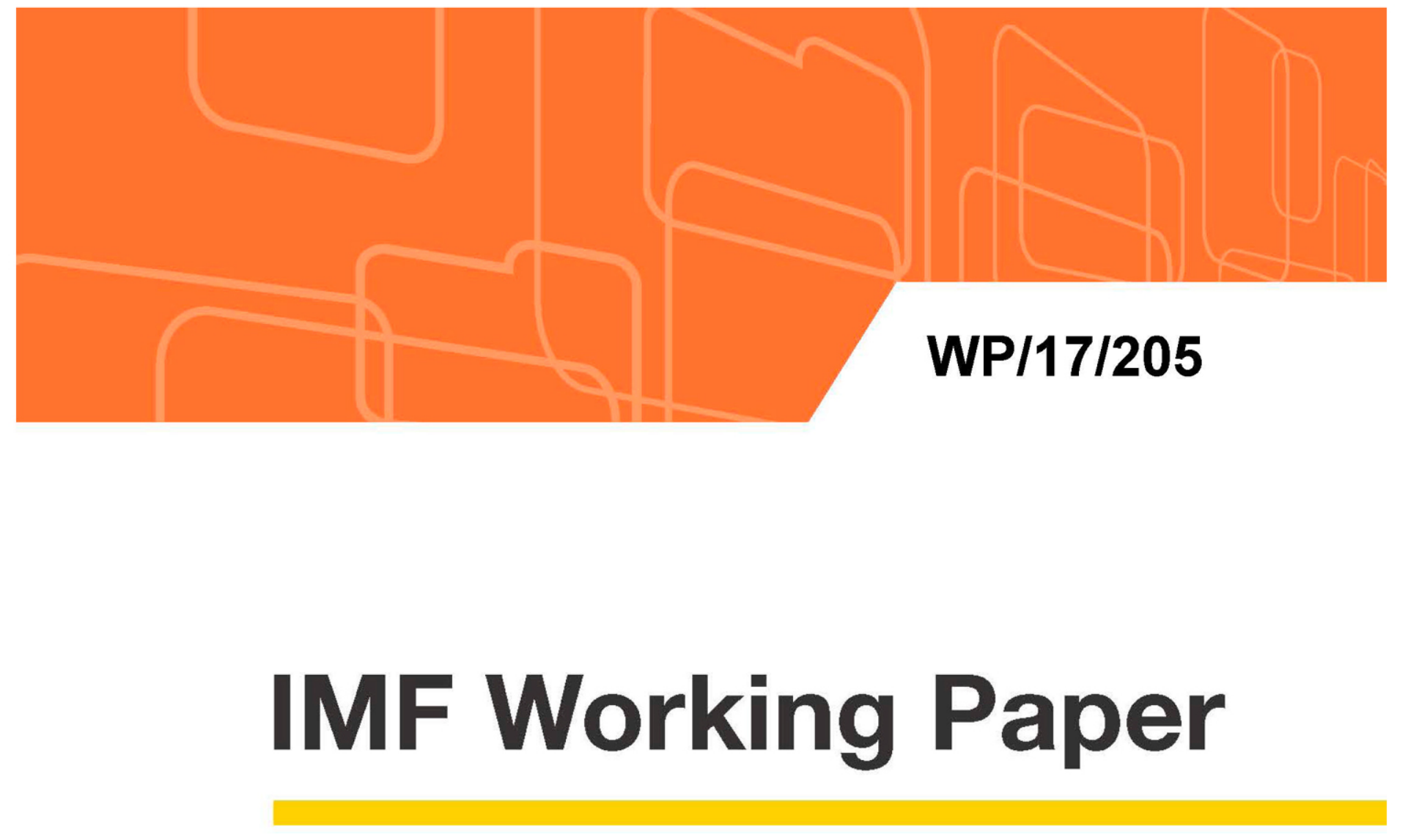

\title{
Indexing Structural Distortion: Sectoral Productivity, Structural Change and Growth
}

\author{
Sakai Ando and Koffie Nassar
}

IMF Working Papers describe research in progress by the author(s) and are published to elicit comments and to encourage debate. The views expressed in IMF Working Papers are those of the author(s) and do not necessarily represent the views of the IMF, its Executive Board, or IMF management.
I N
T R
N A T
N A L
M
N E T A R Y
F U N D 


\title{
WP/17/205
}

\section{IMF Working Paper}

\section{Indexing Structural Distortion: Sectoral Productivity, Structural Change and Growth}

\author{
Sakai Ando and Koffie Nassar
}

IMF Working Papers describe research in progress by the author(s) and are published to elicit comments and to encourage debate. The views expressed in IMF Working Papers are those of the author(s) and do not necessarily represent the views of the IMF, its Executive Board, or IMF management.
| N T E R N A T | O N A L
$M O N E$ T A R Y
F U N D 


\title{
IMF Working Paper
}

African Department

\section{Indexing Structural Distortion: Sectoral Productivity, Structural Change and Growth ${ }^{1}$ Prepared by Sakai Ando ${ }^{2}$ and Koffie Nassar}

Authorized for distribution by Ricardo Velloso

September 2017

\section{IMF Working Papers describe research in progress by the author(s) and are published to elicit comments and to encourage debate. The views expressed in IMF Working Papers are those of the author(s) and do not necessarily represent the views of the IMF, its Executive Board, or IMF management.}

\begin{abstract}
This paper proposes a new index of sectoral labor distortion using employment and valueadded shares. We show that this index is highly correlated with growth both crosssectionally and over time. We also use it to compare the degree of distortion among countries and identify sectors where the potential payoffs in terms of growth from reforms could be large. The regression analysis in the paper shows that education and various structural reforms have potential to improve the efficiency of sectoral labor allocation.

JEL Classification Numbers: J24, L15, N10, O47

Keywords: sectoral distortion, growth, index, productivity, structural change Author's E-Mail Address: sa3016@,columbia.edu, knassar@imf.org

\footnotetext{
${ }^{1}$ The authors would like to thank Aidar Abdychev, Emre Alper, Gregory Auclair, Nicoletta Batini, Paul Cashin, Manuk Ghazanchyan, Tryggvi Gudmundsson, Ali Mansoor, Kiminori Matsuyama, Montfort Mlachila, Alexandro Mourmouras, Anta Ndoye, Alasdair Scott, Axel Schimmelpfennig, and Ricardo Velloso for their encouragement and useful comments. Efua Tawiah and Jean Vibar provided excellent editorial assistance. Any remaining errors and omissions, of course, are the authors' sole responsibility.

2 The paper's empirical work was mainly conducted when Sakai Ando was a summer intern at the Fund in 2016.
} 


\section{TABLE OF CONTENTS}

ABSTRACT,

I. INTRODUCTION

II. LITERATURE REVIEW

III. STRUCTURAL DISTORTION: THEORY

IV. STRUCTURAL DISTORTION: EMPIRICS

A. Ternary Plot

B. Two-Way Plot

V. REGRESSION ANALYSIS

VI. CONCLUDING REMARKS

REFERENCES

\section{APPENDICES}

I. Tables $\underline{17}$

II. Data $\underline{23}$

III. The Model

IV. Ternary Plots

27

V. $d_{i} d_{i}$ Plots

34




\section{INTRODUCTION}

In recent years, there has been increased focus on structural reforms to support productivity growth. ${ }^{3}$ In the literature, declining productivity growth can be indicative of several things, including slowing human and physical capital accumulation, declining pace of sector-specific innovation, institutional and regulatory rigidities that stifle competition and induce slow uptake of existing technologies, and structural shifts to lower productivity sectors. ${ }^{4}$ At the same time, it is recognized that reallocation of resources within and across sectors can lead to higher productivity growth, if driven by technological change and efficient resource allocation. ${ }^{5}$ However, the empirical literature has been hamstrung by lack of reliable cross-country data, especially for developing countries. It is in this context that a new industry-level cross-country dataset that includes developing and low income countries by Timmer et al. (2014) has opened new avenues for research on productivity growth. ${ }^{6}$

Our paper proposes a new index for diagnosing structural distortion using the dataset created by Timmer et al. (2014). The index, defined as the gap between sectoral employment share and valueadded share vectors, possesses several desirable properties. First, a higher efficiency of resource allocation is characterized by the index converging to zero, with non-zero numbers indicating the degree of sectoral distortion. Second, the index allows for comparability among countries and over time within countries, without the need for price adjustment. Third, the index is negatively associated with economic growth both cross-sectionally and over time.

To motivate our analysis, we visualize structural change using ternary plots, which are explained in Section IV. ${ }^{7}$ In the current literature, a typical way of visualizing structural change is a two-way plot of sectoral shares against real gross domestic product (GDP) growth and time series of sectoral shares, as in Herrendorf et al. (2014) and Jorgenson and Timmer (2011). With ternary plots, there is only one moving object for each concept of economic structure. Therefore, it is easy to see the structural change of an economy in terms of both value-added and employment by

\footnotetext{
${ }^{3}$ Productivity gains are key long-term drivers of living standards. According to Dabla-Norris et al. (2013a), in emerging and developing countries, productivity-enhancing structural reforms are needed to boost technological catchup, facilitate structural transformation into higher productivity sectors and new activities, and better allocate existing resources in the economy. Sánchez et al. (2017) note that one challenge that governments face in Europe, particularly since the global financial crisis of 2007-08, is that productivity growth has been decelerating in most European economies.

${ }^{4}$ See, for example, Dabla-Norris et at. (2013a).

${ }^{5}$ See, for example, McMillan, Rodrik and Verguzco-Gallo (2014).

${ }^{6}$ The database is compiled as a product of a research project financed by the European Commission.

${ }^{7}$ This visualization method is not new in economics. For instance, Leamer (1987) makes use of an endowment triangle and Cox (2004) shows a ternary plot of US civilian labor force.
} 
tracing two points in a simplex. This simplicity enables us to find a new pattern and to motivate our index of structural distortion.

Our contribution to the literature is twofold. First, while the methods used in the current literature concentrate on disaggregating change of total productivity between two periods, our index focuses on the current level of structural distortion in each time-period. Since change can be calculated from level data, our index captures both where an economy is and where it goes in a unified manner, which makes it an informative complement to the methodology currently used in the literature. Second, for policy making purposes, our index identifies sectors where potential gains in terms of productivity growth from reforms could be large.

In addition, this paper conducts regression analysis to identify policy variables that can potentially help reduce structural distortion. The evidence suggests that the most important determinant is education, which is intuitive, given that skills are necessary for labor mobility. The evidence also suggests that political freedom, as well as agriculture, trade and bank reforms can reduce structural distortions, although their effects vary depending on the region and level of development. The main assumptions that underpin our index are that high labor productivity sectors attract more people and that capital is owned by people in the sector. ${ }^{8}$

There are limitations, however, to the use of the index. First, the model relies on strong assumptions regarding the functioning of markets and abstracts from possible labor and product market distortions that, if present, may impact the results. Second, the regression analysis is intended to provide correlation between the index and other policy variables - it does not establish causality. Third, the index is a first step in determining which sectors are worth more thorough investigation.

The remainder of the paper is organized into five sections. After reviewing the literature in section II, we define the new index and explain its theoretical properties in section III. We then show that the index is relevant for growth and structural change in section IV. Regression analysis is carried out in section V. Section VI concludes. Appendices provide a general equilibrium model consistent with the index and describe the data.

\section{LiteratURE REVIEW}

The literature on structural transformation has evolved over time. Historically, the organizing framework for most empirical growth research has been the one-sector neoclassical growth model as formulated by Solow (1956) and Swan (1956). This model emphasizes the role of technology for long-term growth and has been criticized for (i) not explaining how technological progress could be accelerated; (ii) considering invention, innovation and ingenuity to be exogenous; and (iii) the fact that capital deepening leads to diminishing returns.

${ }^{8}$ All the assumptions that underpin the index are provided in the theoretical model presented in Appendix III. 
While many economists still view "capital accumulation" as the key to growth and advocate policies to increase savings, a growing number of economists have come to view innovation, and investment in skills and abilities of the work force as the key to boosting productivity and growth. For example, Lucas (1988) and Romer $(1986,1990)$ focus on human capital and technological innovation, respectively. On their part, Dixit and Stiglitz (1977) draw attention to the role of differentiated products and increasing returns to scale.

A recent innovation is to disaggregate total productivity growth into growth at the sector level. Models developed in this context can be characterized as following the theory of resource misallocation (Restuccia and Rogerson, 2008). This theory states that frictions, due to various factors, prevent the efficient use of resources, resulting in a low aggregate factor productivity (Aoki, 2008). Against this background, models have been proposed to, among other things, analyze the effect of the removal of distortions on sector-level resource allocation in Colombia (de Melo, 1977), the magnitude of barriers to resource allocation between the agricultural and nonagricultural sectors (Restuccia, Yang and Zhu, 2008; and Vollrath, 2009), how resource misallocation at manufacturing-plant level affects aggregate total factor productivity in China, India and the United States (Hsieh and Klenow, 2007), the effect of sector-level resource misallocation on aggregate total factor productivity in Japan (Miyagawa, Fukao, Hamagata, and Takizawa, 2008), and the extent to which resource misallocation explains the difference in aggregate productivity across advanced economies (Aoki, 2008).

Recent papers that use indices of structural transformation include McMillan and Rodrik (2011), McMillan et al. (2014), Timmer et al. (2014), and Vries et al. (2015). ${ }^{9}$ McMillan and Rodrick (2011) show that changes in overall productivity can be disaggregated into changes of productivity within sectors and changes in the allocation of labor between sectors (or structural change). While World Bank (2008) finds within-sector productivity improvements to be the drivers of productivity growth in Eastern Europe and the Former Soviet Union during 1999-2004, Duarte and Restuccia (2010) and Herrendorf, Rogerson and Valentinyi (2011) find structural change to be a fundamental driver of long-term development in advanced economies. Given recent improvements in the quality and availability of data, including for developing countries, we propose a new index that not only accounts for salient features of the empirical literature, but also delivers new and sharper insights into issues of interest.

\footnotetext{
${ }^{9}$ Herrendorf et al. (2014) provides an extensive review of the literature on structural change and economic growth.
} 


\section{Structural Distortion: TheOry}

To define the new index, let us assume a country, year and number of sectors $N$. Let $V A_{i}$ and $E_{i}$ be the value-added and employment of sector $i$, respectively. ${ }^{10}$ Employment $E_{i}$ is the number persons engaged, i.e., employers, employees and the self-employed. We define the Euclid distance between the value-added and employment share vectors as

$$
d_{i}:=\frac{E_{i}}{\sum_{k} E_{k}}-\frac{V A_{i}}{\sum_{k} V A_{k}}, \quad d:=\sqrt{\sum_{i} d_{i}^{2}} .
$$

Note that zero distance $d=0$ is equivalent to sectoral productivity equalization.

$$
\frac{E_{i}}{\sum_{k} E_{k}}=\frac{V A_{i}}{\sum_{k} V A_{k}} \forall i \Leftrightarrow P_{i}:=\frac{V A_{i}}{E_{i}}=P:=\frac{\sum_{k} V A_{k}}{\sum_{k} E_{k}} \forall i .
$$

Therefore, mathematically, the distance $d$ provides information on the dispersion of sectoral productivities. Since, under free entry, people have incentive to move to high productivity sectors, we expect $d \rightarrow 0$ unless there are some impediments preventing the convergence. In this sense, $d$ represents how distorted an entire economy is. The larger $d$ is, the more distorted the economy. Accordingly, $d_{i}$ represents the distortion of sector $i$. When $d_{i}>0$, there are too many people engaged in the sector $i$, and vice versa.

We note two points about the rationale behind the index $\left\{d, d_{i}\right\}$. First, by the definition of data $\left\{V A_{i}, E_{i}\right\}_{i}$, free entry or "people move" means both "workers moving to another sector as employees" and "entrepreneurs moving to another sector as employers". Hence, the mere fact that a sector is capital intensive does not mean that people cannot move to the sector. Therefore, if people do not move, it is because there are impediments preventing them from moving, such as reallocation costs, lack of required skills, excess regulation, lack of financial access, and other factors that affect firm dynamics. Second, the argument is limited to productivity equalization among sectors as shown in the model in Appendix III. As a result, this paper does not address issues relating to inequality of productivity within each sector.

A relevant question is "why should we use $\left\{d, d_{i}\right\}$ as indices of aggregate and sectoral distortions if all we want to see is how dispersed sectoral productivities are?" We provide three theoretical justifications in this section, and two empirical justifications in the next section.

First, $\left\{d, d_{i}\right\}$ allows country and time comparisons. Since $\left\{d, d_{i}\right\}$ is free of the unit of value-added $\left\{V A_{i}\right\}_{i}$ as is clear from equation (1), one does not have to adjust the currency and price level by

\footnotetext{
${ }^{10}$ It does not matter if the unit of $V A_{i}$ is real or nominal. For ease of reference, we consider the unit to be nominal local currency.
} 
taking a particular average of exchange rates or choose a specific deflator. In other words, the unitfree property of $d$ allows it to extract the pure structural part of productivity dispersion from raw data, without it being contaminated by other non-structural factors that affect exchange rates and inflation. This ideal property is a distinctive characteristic of $\left\{d, d_{i}\right\}$, which sets it apart from other unit-dependent indices, such as the standard deviation of sectoral productivity $\left\{P_{i}\right\}_{i} \cdot{ }^{11}$

Second, $\left\{d, d_{i}\right\}$ takes into account the importance of each sector. To see this, note that a straightforward manipulation reveals that $d_{i}$ is the percentage deviation of sectoral productivity from aggregate productivity weighted by the employment size of the sector.

$$
d_{i}=-\frac{E_{i}}{\sum_{k} E_{k}}\left(\frac{P_{i}-P}{P}\right)
$$

The fact that $d_{i}$ is weighted is important to gauge the breadth and depth of the structural problem because, more often than not, the sectors with the highest productivity are the smallest relative to the others. Therefore, for policy makers interested in addressing the most important distortions, a high $d_{i}$ is more informative than a high sectoral productivity $P_{i}$. An immediate corollary is that sectoral distortion $\left\{d_{i}\right\}_{i}$ does not necessarily preserve the order of sectoral productivity $\left\{P_{i}\right\}_{i}$, i.e.,

$$
d_{i} \geq d_{j} \leftrightarrow P_{i} \leq P_{j} .{ }^{12}
$$

Third, $\left\{d, d_{i}\right\}$ has ideal numerical properties. For instance, assuming $V A_{i} \geq 0,\left\{d, d_{i}\right\}$ is bounded from both sides, there is no need to de-trend or rescale time series data.

$$
-1 \leq d_{i} \leq 1, \quad 0 \leq d \leq \sqrt{N}
$$

These inequalities may not be immediately obvious from equation (3) but is straightforward from equation (1). One can also observe that sectoral distortion $\left\{d_{i}\right\}_{i}$ adds up to 0 :

$$
\sum_{i} d_{i}=0 .
$$

Mathematically, equation (6) implies that $d$ is the standard deviation of $\left\{d_{i}\right\}$, with uniform probability over all sectors. An economic implication of equation (6) is that whenever there is a

${ }^{11}$ Of course, the unit-free property does not hold if different price indices are used for different sectors to go back and forth between real and nominal.

12 To see this formally, note the following identity

$$
P_{i}-P_{j}=-\frac{\sum_{k} V A_{k}}{E_{i}}\left\{d_{i}-d_{j}+\left(1-\frac{E_{i}}{E_{j}}\right) d_{j}\right\}
$$

Hence, even if the two sectors have the same sectoral distances $d_{i}=d_{j}$, the order of sectoral productivities can still vary depending on the employment sizes of the two sectors. 
distorted sector, there must be another sector that is distorted in the opposite direction to absorb the original distortion. This is useful for policy making purposes because when sector $i$ has too few people, $\left\{d_{i}\right\}$ always tells the sector with excess human resources.

To better appreciate these theoretical properties of the new index, we use the GGDC 10-sector database by Timmer et al. (2014) to plot sectoral productivity $\left\{P_{i}\right\}_{i}$ and distortion $\left\{d_{i}\right\}_{i}$ for several countries. See Appendix II for the process used in cleaning the data, as well as the sources of the other data used in the rest of the paper. Figure 1 below shows the time series of the two concepts for South Africa. As depicted in the graph on the left, the productivity lines tend to diverge. While mining and utilities sectors show up at the top, it is not clear how to compare the economic structure over time since the lines are non-stationary. This pattern remains unchanged when nominal productivity is replaced with real productivity. In contrast, $d_{i}$, as shown in the graph on the right, captures excess labor in the agriculture sector since 1960, and convergence of labor productivity among other sectors, including the mining sector. While the causes of these structural shifts are important from policy making perspective, they are beyond the scope of this paper. The point we want to make here is that plotting $\left\{d_{i}\right\}_{i}$ is a better way to capture structural distortion than plotting $\left\{P_{i}\right\}_{i}$.

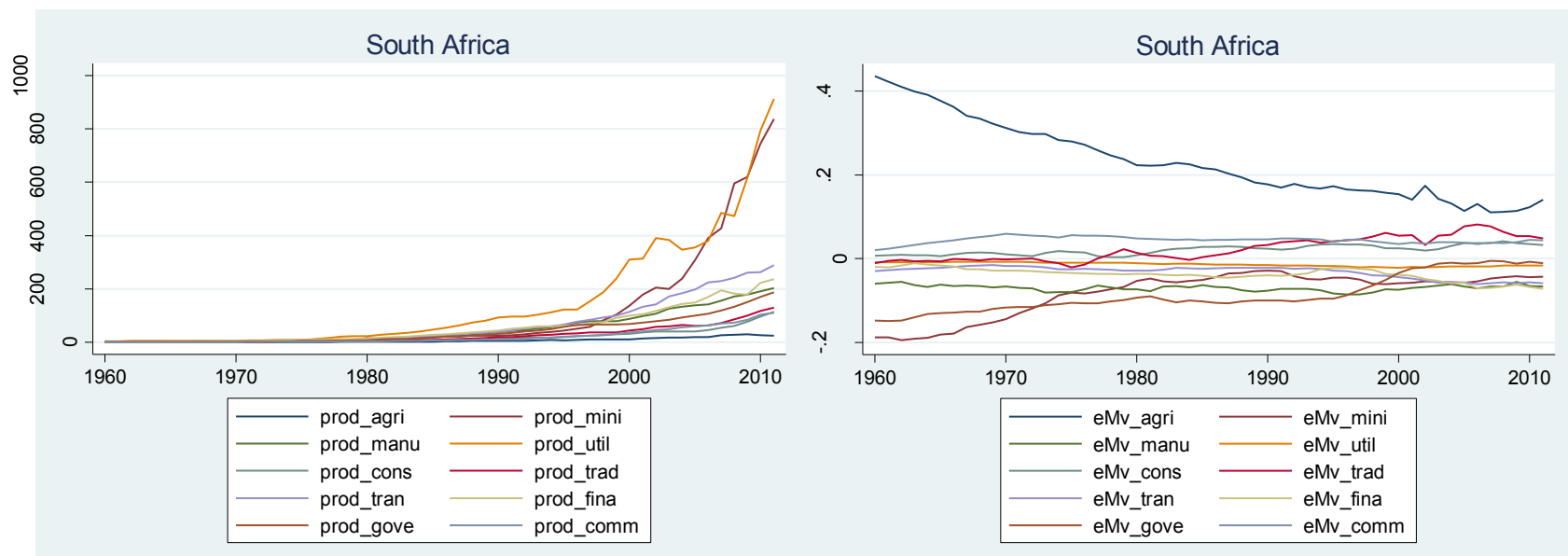

Figure 1. The graph on the left plots nominal sectoral productivities in local currency for 10 sectors, consisting of agriculture, mining, utilities, construction, trade, restaurants and hotel, transport, storage and communication, finance, insurance, real estate and business services, government services, community, social and personal services. Legend begins with "prod" to remind that this is productivity, and ends with the first four letters of each sector. The graph on the right plots sectoral distortion for the same 10 sectors. Legend begins with "eMv" to remind that it is employment share minus value added share so that the line above zero means there are too many people engaged in the sector. Plots for other countries are relegated to Appendix $V$.

We emphasize the difference between our methodology and the shift accounting analysis used by McMillan et al. (2014), Vries et al. (2015) and others as follows. Shift accounting analysis shows whether a structural change contributes to aggregate productivity change over a certain period of time. However, shift accounting is not informative when there is no change in economic structure and aggregate productivity. This property of shift accounting is unsatisfactory because no structural change does not necessarily mean that there is no need for structural change. As the agriculture time series in the graph on the right of Figure 1 suggests, the sector which is constantly 
distorted without structural change for a long period of time might be the one that needs structural change the most from the point of view of efficient resource allocation. Thus, the fact that the distortion index $\left\{d, d_{i}\right\}$ can capture both level and change of economic structure makes it an informative complement to the shift accounting analysis.

\section{STRUCTURAL Distortion: EMPIRICS}

In this section, we show in two ways that $\left(d, d_{i}\right)$ is a relevant object for growth and structural change from an empirical point of view. First, we use ternary plots to show structural change in the entire economy. It visually suggests that the distance $d$ is an informative index of growth levels both cross-sectionally and within each country over time. Second, we use two-way plots to further investigate the relationship between distance $d$ and growth.

\section{A. Ternary Plot}

One of the most efficient ways to visualize structural change in an economy is via ternary plots. The basic idea of a ternary plot is to represent an economy as a point on the simplex, and keep track of it over time. To be precise, let us assume an economy can be divided into three sectors $N=3$, and let $s_{t}=\left(s_{1 t}, s_{2 t}, s_{3 t}\right) \in \mathbb{R}_{+}^{3}$ be the vector of sectoral shares of any concept at time $t$. Then, $s_{t}$ is a point on the simplex $\Delta$

$$
s_{t} \in \Delta:=\left\{\left(x_{1}, x_{2}, x_{3}\right) \in \mathbb{R}_{+}^{3}: x_{1}+x_{2}+x_{3}=1\right\} .
$$

Put differently, by depicting the trajectory $\left(s_{t}\right)_{t=1}^{T} \subset \Delta$, ternary plot combines the data of $3 \times T$ matrix into a line in a triangle.

An obvious limitation of a ternary plot is that it can only depict three sectors. Hence, the way the economy is partitioned matters. Normally, an economy can be partitioned as \{agriculture, manufacturing, services\}. However, for countries that are heavily dependent on agriculture and mining, \{agriculture, mining, the rest\} partition might make more sense. In this paper, we adopt \{primary, secondary, tertiary\} partition where the primary sector combines agriculture and mining sectors, secondary sector combines manufacturing and construction, and tertiary is the rest.

The ternary plots for all countries in our dataset are presented in Appendix IV. The tendency is that, on average, the more developed a country is, the closer the two points are both crosssectionally and within countries over time. We will see more examples in the next section. Another observation from the ternary plot is that economies may move from the primary sector to the tertiary sector. Note that the distance $d$ is, at least a priori, an independent concept of the direction of structural change. In other words, an economy that moves its resources directly from the primary sector to the tertiary sector, without first going through the secondary sector, does not portend a high degree of distortion $d$. The index $d$ only indicates, given the direction of structural change, whether resources are allocated efficiently. Therefore, unlike Carmignani and Mandeville 
(2014), we do not have to take a stance on whether "immature" industrialization of developing countries is a good or bad omen.

\section{B. Two-Way Plot}

As discussed above, ternary plot provides a bird's-eye view of the structural change of an economy in the sense that one can literally see how an economy moves by tracing the moving dots. In this section, we magnify one aspect of structural change: the relationship between the distance $d$ and economic growth. For this purpose, we compress sectoral data of $3 \times T$ matrix into a scalar index $d$. This operation allows us to show the impact of the reduction of sectoral distortion on growth over time.
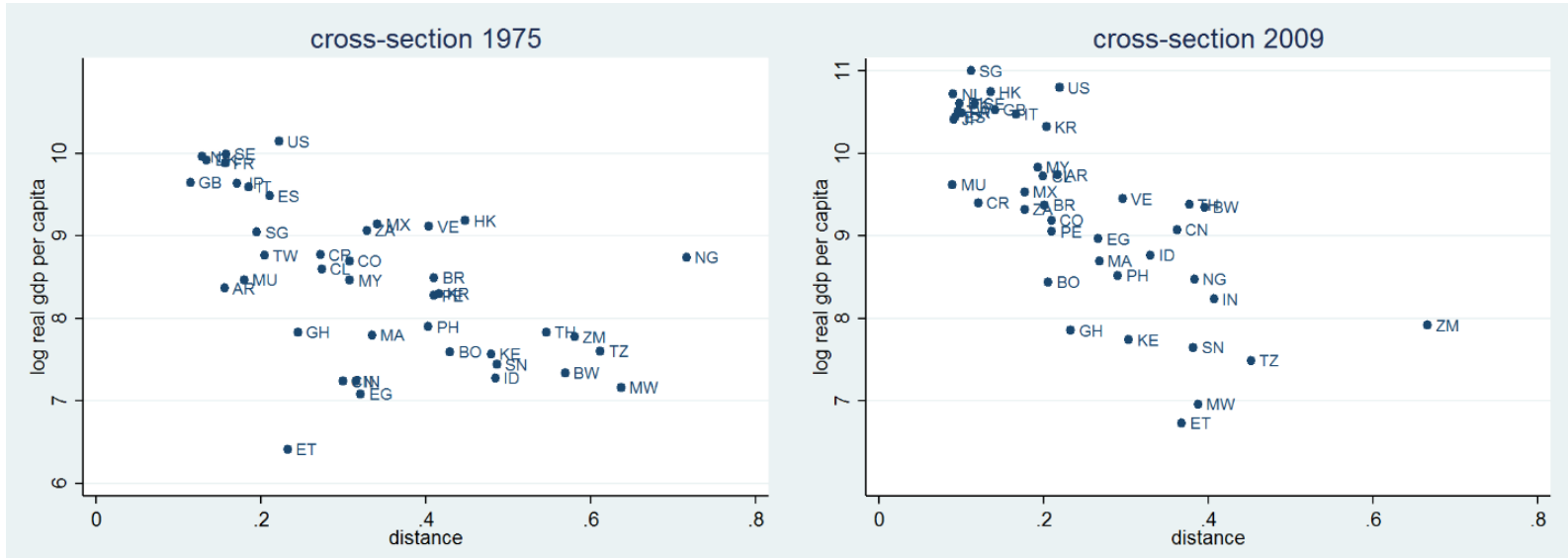

Figure 2. The figure on the left shows the scatter plot of log real GDP per capita against distance d in 1975. The figure on the right shows the same graph for the year 2009. The two graphs have exactly the same ranges and scales in both axes. Country label follows ISO2 as in Appendix I, Table 1.

Figure 2 shows two cross-sectional scatter plots of log GDP per capita against the distortion index $d$ in 1975 and 2009, the earliest and latest years for which we have data for all countries in our sample. It can be seen that a negative relationship between growth and distortion $d$ existed and that it became stronger over time, which is consistent with the hypothesis that improving resource allocation contributes to growth. The gif files (1 and 2) in the data appendix show the full animation of the transition from 1960 to 2010. An observation from the animation is that African countries tend to move faster than others, reflecting either unstable economic structures and/or lower quality of data.

Two observations are noteworthy. First, since the distortion index $d$ is unit-free, one can use Figure 2 to rank countries by the size of their distortion. In Appendix I, Table 2, we present the table of distortion ranking for 2009. Second, not all countries have moved toward the tertiary sector. This is not surprising since growth can take place for many reasons other than through a reduction of inefficient resource allocation. For instance, a new oil field can potentially increase GDP per capita without reducing distortion $d$. Indeed, since structural change can take a longer time than the increase in value-added, positive shocks such as new technologies and new natural 
resource opportunities can increase distortion $d$ in the short run. The fact that an economy can grow without reducing structural distortion does not necessarily undermine the importance of reducing structural distortion. The relevant questions from policy makers' point of view should be whether the economy has the ability to reduce distortion on its own and which structural reforms facilitate the reduction of distortion? We discuss potential policy variables in section $\mathrm{V}$.

Before moving on to regression analysis in section $\mathrm{V}$, we show how $\left\{d, d_{i}\right\}$ can be used in practice. In Appendix V, we plot the $\left\{d, d_{i}\right\}$, as in the right-hand side of Figure 1, for all the countries in our dataset. Statistically, economic growth is highly correlated with the reduction of the structural distortion index. In fact, 27 out of 41 countries have $\mathrm{R}^{2}>0.5$ from 1960 to 2012. ${ }^{13}$ See Appendix I, Table 2 for the complete list of $\mathrm{R}^{2}$ by country. A few observations are worth mentioning. First, some countries grow with increasing distortion. While the slope for some of these countries switch from positive to negative when the data are restricted to the period after 1990, others constantly grow with increasing structural distortion. ${ }^{14}$ Second, some economies have experienced increasing structural distortion after 1990. Third, on average too many people are engaged in the agriculture sector in developing countries. ${ }^{15}$ Fourth, sectoral distortions are much larger in developing countries than in advanced economies. A policy implication of these findings is that there are potential gains in terms of growth from reforms aimed at reallocating resources among sectors and/or within sectors.

\section{REgRESSION ANALYSIS}

In this section, we use regression analysis to find promising correlations between policy variables and our index of structural distortion $d$. Since establishing causality requires well-designed experiments, our analysis should be interpreted as promising candidates rather than a ready-to-use recipe, which has to be crafted in each country's context. Against this background, we choose candidate independent variables from those used by Prati et al. (2012) and Dabla-Norris et al. (2013a and 2013b). The difference between those two papers and ours is that our dependent variable is the index of structural distortion $d$, instead of GDP or each sector's share.

Conceptually, what this means is that, compared with Prati et al. (2012), we are only interested in the part of economic growth that can be associated with efficient resource allocation. Compared with Dabla-Norris (2013a and 2013b), our interest is not so much sectoral shares as how much aggregate distortion can be impacted by policy variables.

Intuitively, since people already have incentives to move to higher productivity sectors, policies that help get rid of impediments should contribute to reducing structural distortion. One variable

\footnotetext{
${ }^{13}$ While a high $\mathrm{R}^{2}$ does not imply causality, this level of correlation is worth emphasizing.

${ }^{14}$ Investigation of what drives these different outcomes are beyond the scope of this paper.

${ }^{15}$ One reason why there are too many in agriculture in developing countries is probably due to the lack of opportunities elsewhere.
} 
that has a broad appeal is education (Saviotti et al., 2016). ${ }^{16}$ To be able to consider other candidates as systematically as possible at the risk of type I error, we regress the distortion index $d$ on independent variables used by Dabla-Norris et al. (2013a and 2013b) and retain only those variables that pass two criteria. First, we require that the p-value of the OLS coefficient be smaller than 0.01 , in order to ensure that the relationship is visually intuitive. Second, to avoid a spurious relationship, we require that the null hypothesis of no co-integration be rejected with a significance level of 0.01 in at least three out of the four panel co-integration tests by Westerlund (2007) of the form:

$$
d_{i t}=\delta_{i}+\alpha_{i}\left(d_{i t-1}+\beta_{i} x_{i t-1}\right)+\alpha_{i 1} \Delta d_{i t-1}+\gamma_{i 1} \Delta x_{i t-1}+e_{i t}
$$

where $d_{i t}$ is the distortion index of country $i$ in year $t, x_{i t}$ is each independent variable in DablaNorris et al. (2013a and 2013b), $\left(\delta_{i}, \alpha_{i}, \beta_{i}, \alpha_{i 1}, \gamma_{i 1}\right)$ are parameters, and $\Delta$ is the difference operator $\Delta d_{i t}:=d_{i t}-d_{i t-1}$. The set of variables that constantly pass these filters is education (secondary education completion rate among the population over age 25 and average years of schooling over age 25). Furthermore, two variables (economic freedom and political freedom) pass the two criteria with higher significance level than 0.1. In addition, we add structural reform variables used in Prati et al. (2012) to assess their impact in reducing distortion. See Appendix II for the full list of independent variables.

With the independent variables $x_{i t}$ selected on the basis of the above procedure, our empirical model is specified as follows:

$$
d_{i t}=\alpha_{i}+\beta^{\prime} x_{i t}+u_{i t}
$$

Appendix I, Table 3 reports the results for the full world sample, advanced economies, emerging and developing economies, and sub-Saharan Africa. See Appendix I, Table 1 for the composition of each sub-group. ${ }^{17}$

We find that the most important variable that can reduce distortion is education especially in developing countries (Tables 3-10). Thus, in the long run, education may improve labor mobility and facilitate the shift of labor from less- to more productive activities. For advanced economies, political and economic freedom explains the reduction in distortion over the past fifty years. For emerging and developing economies, in addition to education, political freedom, and bank and agriculture reforms stand out, reflecting the fact that too many people are trapped in the agriculture sector and without adequate financing. Furthermore, economic freedom and network reforms explain the reduction in distortion in the manufacturing sector. Regarding the sub-Saharan Africa sub-group, agriculture and trade reforms exert strong effect on the reduction of distortion in the

\footnotetext{
${ }^{16}$ Saviotti et al. (2016) discusses the implication of education on structural change and economic development.

${ }^{17}$ Note that when two variables are co-integrated, the estimator is super-consistent. As a result, our inference based on OLS estimates is conservative.
} 
agriculture sector. In addition, economic freedom, and agriculture and trade reforms significantly contribute to the reduction of distortion in the manufacturing sector. In the short run, however, the results above might not hold, since human capital accumulation takes time, but policy intervention can change the economic structure. ${ }^{18}$

\section{CONCLUding REMARKS}

In this paper, we propose a new index of structural distortion and show its theoretical and empirical properties. Also, we show that structural distortions are negatively correlated with growth, that the agriculture sector is the most distorted in developing countries, and that overall distortions are larger in developing countries than in advance economies. Regression results suggest that the most important determinant of distortions is educational attainment, which is intuitive since skills are necessary for labor mobility. The evidence also suggests that political and economic freedom, as well as agriculture, trade and bank reforms, can reduce structural distortions, although their effects vary depending on the region and level of development. Our findings thus lend support to efforts to promote education, to trim regulations that protect sectoral monopolies, to promote trade and financial inclusion, and to help newcomers set up businesses.

\footnotetext{
${ }^{18}$ For instance, in Table 8, the correlation between education and distortion is positive for the manufacturing sector in emerging economies. As can be seen in Appendix V, this phenomenon is driven by a few countries that have adopted various industrial policies and encouraged large FDI inflows. As these policies lead to an increase in labor demand, labor supply might not be able to catch up as fast. As a result, labor productivity could be higher than aggregate productivity growth. In this case, our distortion index suggests the need to foster labor mobility to the higher productive sector.
} 


\section{REFERENCES}

Aoki, S., (2008), "A Simple Accounting Framework for the Effect of Resource Misallocation on Aggregate Productivity." Munich Personal RePEc Archive, http://mpra.ub.uni$\underline{\text { muenchen.de/12506/ }}$

Barro, R. J., \& Lee, J. W. (2013), “A new data set of educational attainment in the world, 1950-2010”. Journal of Development Economics, 104, pp. 184-198.

Beniger, J. R. (1986), The control revolution: technological and economic origins of the information society. Cambridge. Mass: Harvard University Press.

Carmignani, F., \& Mandeville, T. (2014), "Never been industrialized: A tale of African structural Change”. Structural Change and Economic Dynamics, 31, pp. 124-137.

Christiansen, L., Schindler, M., \& Tressel, T. (2013), “Growth and structural reforms: A new Assessment”. Journal of International Economics, 89(2), pp. 347-356.

Cox, N. J. (2004), "Speaking Stata: Graphing categorical and compositional data". Stata Journal, 4, pp. 190-215. Retrieved from http ://ageconsearch.umn.edu/bitstream/116238/2/sjart_gr0004.gdp.

Dabla-Norris, E., Ho, G., Kochhar, K., Kyobe, A., \& Tchaidze, R. (2013a), “Anchoring Growth: The Importance of Productivity-Enhancing Reforms in Emerging Market and Developing Economies”. IMF Staff Discussion Notes, 13(8), 1. Doi:10.5089/9781616357290.006.

Dabla-Norris, E., Thomas, A. H., Garcia-Verdu, R., \& Chen, Y. (2013b), "Benchmarking Structural Transformation Across the World". IMF Working Papers, 13(176), 1. Doi:10.5089/9781484359662.001.

De Melo, J. A. P., (1977), "Distortions in the Factor Market: Some General Equilibrium Estimates." Review of Economics and Statistics 59, pp. 398-405.

Dixit, K. A., and J. E. Stiglitz, (1977), "Monopolistic Competition and Optimal Product Diversity", The American Economic Review, Vol. 67. No. 3, pp. 297-308.

Duarte, M. and D. Restuccia, (2010), "The Role of the Structural Transformation in Aggregate Productivity," The Quarterly Journal of Economics, 125(1), pp: 129-173.

Feenstra, R. C., Inklaar, R., \& Timmer, M. P. (2015), "The Next Generation of the Penn World Table". American Economic Review, 105(10), pp. 3150-3182.

Foundation, T. H. (2015), "Index of economic freedom”. Oxford University Press, USA.

Gwartney, J., Lawson, R., \& Hall, J. (2015), “2015 Economic Freedom Dataset”. Economic Freedom of the World. Retrieved from http://www.freetheworld.com/datasets_efw.html. 
Herrendorf, B., Rogerson, R., \& Valentinyi, Á. (2014), Chapter 6 - Growth and Structural Transformation. In P. A. Durlauf (Ed.), Handbook of Economic Growth (Vol 2, pp. 855941). Elsevier. Retrieved from http://www.sciencedirect.com/science/article/pii/B9780444535405000069.

Hsieh, C. T. and P. J. Klenow, (2007), "Misallocation and Manufacturing TFP in China and India.” NBER Working Papers 13290, National Bureau of Economic Research, Inc.

Kanbur S.M. (1979), “Of Risk Taking and the Personal Distribution of Income”. Journal of Political Economy, Volume 87, no. 4 (Aug., 1979): pp. 769-797.

Jorgenson, D. W., \& Timmer, M. P. (2011), "Structural Change in Advanced Nations: A New Set of Stylised Facts”. Scandinavian Journal of Economics, 113(1), pp. 1-29.

Leamer, E. E. (1987), "Paths of Development in the Three-Factor, n-Good General Equilibrium Model”. Journal of Political Economy. 95(5), pp. 961-999. Retrieved from http://www.jstor.org/stable/1833125.

Leigh, L., A. Mansoor, and I. M. Fund, (2016), Africa on the Move. International Monetary Fund: Washington, DC.

Lucas, E. R. (1988), “On the Mechanics of Economic Development”, Journal of Monetary Economics, North-Holland, 22, pp. 3-43.

McMillan, M., \& Rodrik, D. (2011), "Globalization, Structural Change and Productivity Growth". Tech. rep., National Bureau of Economic Research, Cambridge. Retrieved from http://www.nber.org/papers/w17143.pdf.

McMillan, M., Rodrik, D., \& Verduzco-Gallo, Í. (2014), Globalization, Structural Change, and Productivity Growth, with an Update on Africa. World Development. 63, pp. 11-32. Doi:10.1016/j.worlddev.2013.10.012.

Miyagawa, T., K. Fukao, S. Hamagata, and M. Takizawa, (2008), "Efficiency of Sector-Level Resource Allocation (in Japan)." In Fukao, K. and T. Miyagawa (Eds.). Productivity and Japan's Economic Growth: Industry-Level and Firm-Level Studies Based on the JIP Database. Tokyo: University of Tokyo Press, pp. 129-155.

Oser, R. D., \& Jedwab, R. (2013), "Is Structural Change in Sub-Saharan Africa Different? New Historical Evidence from Ghana". Working paper.

Prati, A., Onorato, M. G., \& Papageorgiou, C. (2012), "Which Reforms Work and under What Institutional Environment? Evidence from a New Data Set on Structural Reforms". Review of Economics and Statistics. 95(3), pp.946-968. Doi:10.1162/REST a 00307.

Restuccia, D. and R. Rogerson, (2008), "Policy Distortions and Aggregate Productivity with Heterogeneous Establishments." Review of Economic Dynamics, 11, pp. 707-720. 
Restuccia, D., D. T. Yang, and X. Zhu, (2008), "Agriculture and Aggregate Producivity: A Quantitative Cross-Country Analysis.” Journal of Monetary Economics, 55, pp. 234-250.

Romer, M. P. (1986), "Increasing Returns and Long-Run Growth", The Journal of Political Economy, Vol. 94, No. 5, pp. 1002-1037

Romer, M. P. (1990), "Endogenous Technical Change”, The Journal of Political Economy, Vol 98, No. 5, pp. S71-S102.

Sánchez A. C., and N. Ruiz, (2017), « Structural reforms to revive growth in Europe: necessary but not sufficient". OECD ECOSCOPE, https://oecdecoscope.wordpress.com/2017/02/09/structural-reforms-to-revive-growth-ineurope-necessary-but-not-sufficient/.

Saviotti, P. P., Pyka, A., \& Jun, B. (2016). "Education, structural change and economic development". Structural Change and Economic Dynamics, 38, pp. 55-68.

Doi:10.1016/j.strueco.2016.04.002.

Stefan, D., Holmberg, S., Rothstein, B., Khomenko, A., \& Svensson, R. (2016). The Quality of Government Basic Dataset, version Jan16. University of Gothenburg: The Quality of Government Institute. Retrieved from http://www.qog.pol.gu.se doi:10.18157/QoBasJan19.

Solow, R. M., 1956, “A Contribution to the Theory of Economic Growth.” Quarterly Journal of Economics, Vol. 70, No. 1, pp. 65-94.

Swan, T. W., "Economic Growth and Capital Accumulation". Economic Record, Vol. 32, pp. $334-361$.

Timmer, M., Vries, G. d., \& Vries, K. d. (2014). "Patterns of Structural Change in Developing Countries". GGDC research memorandum 149. Retrieved from http://www.reg.nl/research/ggdc/data/10-sector-database.

Vries, G. d., Timmer, M., \& Vries, K. d. (2015). "Structural Transformation in Africa: Static Gains, Dynamic Losses”. The Journal of Development Studies, 51(6), pp.674-688. Doi:10.1080/00220388.2014.997222.

Westerlund, J. (2007). "Testing for Error Correction in Panel Data". Oxford Bulletin of Economics and Statistics, 69(6), pp.709-748. Doi:10.1111/j.1468-

0084.2007.00477.x.Knass.

World Bank, (2008), Unleashing Prosperity, Productivity Growth in Eastern Europe and the Former Soviet Union, Washington D.C.: World Bank. 


\section{Appendix I. Tables}

Table 1. List of Countries, ISO2 and Group ( 1 if the country is in the group)

\begin{tabular}{|c|c|c|c|c|}
\hline country & ISO2 & $\begin{array}{r}\text { Advanced } \\
\text { economies }\end{array}$ & $\begin{array}{r}\text { Emerging and } \\
\text { developing economies }\end{array}$ & $\begin{array}{r}\text { Sub-Saharan } \\
\text { Africa }\end{array}$ \\
\hline Argentina & $A R$ & 0 & 1 & 0 \\
\hline Bolivia & $\mathrm{BO}$ & 0 & 1 & 0 \\
\hline Botswana & BW & 0 & 1 & 1 \\
\hline Brazil & $\mathrm{BR}$ & 0 & 1 & 0 \\
\hline Chile & $\mathrm{CL}$ & 0 & 1 & 0 \\
\hline China & $\mathrm{CN}$ & 0 & 1 & 0 \\
\hline Colombia & $\mathrm{CO}$ & 0 & 1 & 0 \\
\hline Costa Rica & $\mathrm{CR}$ & 0 & 1 & 0 \\
\hline Denmark & DK & 1 & 0 & 0 \\
\hline Egypt & $\mathrm{EG}$ & 0 & 1 & 0 \\
\hline Ethiopia & ET & 0 & 1 & 1 \\
\hline France & $\mathrm{FR}$ & 1 & 0 & 0 \\
\hline Ghana & $\mathrm{GH}$ & 0 & 1 & 1 \\
\hline Hong Kong SAR & $\mathrm{HK}$ & 1 & 0 & 0 \\
\hline India & IN & 0 & 1 & 0 \\
\hline Indonesia & ID & 0 & 1 & 0 \\
\hline Italy & IT & 1 & 0 & 0 \\
\hline Japan & $J P$ & 1 & 0 & 0 \\
\hline Kenya & KE & 0 & 1 & 1 \\
\hline Korea & $\mathrm{KR}$ & 1 & 0 & 0 \\
\hline Malawi & MW & 0 & 1 & 1 \\
\hline Malaysia & MY & 0 & 1 & 0 \\
\hline Mauritius & $\mathrm{MU}$ & 0 & 1 & 1 \\
\hline Mexico & $\mathrm{MX}$ & 0 & 1 & 0 \\
\hline Morocco & $\mathrm{MA}$ & 0 & 1 & 0 \\
\hline Netherlands & $\mathrm{NL}$ & 1 & 0 & 0 \\
\hline Nigeria & NG & 0 & 1 & 1 \\
\hline Peru & PE & 0 & 1 & 0 \\
\hline Philippines & $\mathrm{PH}$ & 0 & 1 & 0 \\
\hline Senegal & SN & 0 & 1 & 1 \\
\hline Singapore & SG & 1 & 0 & 0 \\
\hline South Africa & ZA & 0 & 1 & 1 \\
\hline Spain & ES & 1 & 0 & 0 \\
\hline Sweden & SE & 1 & 0 & 0 \\
\hline Taiwan Province of China & TW & 1 & 0 & 0 \\
\hline Tanzania & $\mathrm{TZ}$ & 0 & 1 & 1 \\
\hline Thailand & $\mathrm{TH}$ & 0 & 1 & 0 \\
\hline United Kingdom & $\mathrm{GB}$ & 1 & 0 & 0 \\
\hline United States & US & 1 & 0 & 0 \\
\hline Venezuela & VE & 0 & 1 & 0 \\
\hline Zambia & ZM & 0 & 1 & 1 \\
\hline
\end{tabular}




\section{Appendix I. Tables}

Table 2. Distortion Ranking (left) and $R^{2}$ of Log Real GDP per Capita vs $d$

\begin{tabular}{|c|c|c|c|c|}
\hline ranking & country & $\begin{array}{l}\text { Distortion } \\
\text { index } d(2009)\end{array}$ & country & $\begin{array}{c}R^{2} \\
(1960-2012)\end{array}$ \\
\hline 1 & Mauritius & 0.09 & Hong Kong SAR & 0.98 \\
\hline 2 & Netherlands & 0.09 & Japan & 0.96 \\
\hline 3 & Japan & 0.09 & Brazil & 0.94 \\
\hline 4 & Spain & 0.09 & Korea & 0.92 \\
\hline 5 & Taiwan Province of China & 0.10 & Costa Rica & 0.91 \\
\hline 6 & Denmark & 0.10 & Taiwan Province of China & 0.88 \\
\hline 7 & France & 0.10 & Argentina & 0.88 \\
\hline 8 & Singapore & 0.11 & Mexico & 0.86 \\
\hline 9 & Sweden & 0.12 & Colombia & 0.86 \\
\hline 10 & Costa Rica & 0.12 & Mauritius & 0.84 \\
\hline 11 & Hong Kong SAR & 0.14 & France & 0.83 \\
\hline 12 & United Kingdom & 0.14 & Spain & 0.82 \\
\hline 13 & Italy & 0.17 & Bolivia & 0.80 \\
\hline 14 & South Africa & 0.18 & Malaysia & 0.78 \\
\hline 15 & Mexico & 0.18 & Netherlands & 0.78 \\
\hline 16 & Malaysia & 0.19 & Indonesia & 0.77 \\
\hline 17 & Chile & 0.20 & Denmark & 0.77 \\
\hline 18 & Brazil & 0.20 & Italy & 0.73 \\
\hline 19 & Korea & 0.20 & China & 0.73 \\
\hline 20 & Bolivia & 0.21 & Philippines & 0.72 \\
\hline 21 & Colombia & 0.21 & South Africa & 0.71 \\
\hline 22 & Peru & 0.21 & United States & 0.70 \\
\hline 23 & Argentina & 0.22 & Thailand & 0.66 \\
\hline 24 & United States & 0.22 & Sweden & 0.65 \\
\hline 25 & Ghana & 0.23 & Peru & 0.60 \\
\hline 26 & Egypt & 0.27 & Botswana & 0.57 \\
\hline 27 & Morocco & 0.27 & Morocco & 0.50 \\
\hline 28 & Philippines & 0.29 & Chile & 0.48 \\
\hline 29 & Venezuela & 0.30 & India & 0.35 \\
\hline 30 & Kenya & 0.30 & Egypt & 0.35 \\
\hline 31 & Indonesia & 0.33 & Singapore & 0.31 \\
\hline 32 & China & 0.36 & Venezuela & 0.25 \\
\hline 33 & Ethiopia & 0.37 & Senegal & 0.23 \\
\hline 34 & Thailand & 0.38 & Tanzania & 0.20 \\
\hline 35 & Senegal & 0.38 & Zambia & 0.18 \\
\hline 36 & Nigeria & 0.38 & Malawi & 0.18 \\
\hline 37 & Malawi & 0.39 & United Kingdom & 0.16 \\
\hline 38 & Botswana & 0.40 & Ethiopia & 0.09 \\
\hline 39 & India & 0.41 & Nigeria & 0.03 \\
\hline 40 & Tanzania & 0.45 & Kenya & 0.02 \\
\hline 41 & Zambia & 0.67 & Ghana & 0.02 \\
\hline
\end{tabular}




\section{Appendix I. Tables}

Table 3. Total Sample: Distortion

\begin{tabular}{|c|c|c|c|}
\hline VARIABLES & $\begin{array}{c}(1) \\
\text { distortion } \\
\end{array}$ & $\begin{array}{c}(2) \\
\text { distortion } \\
\end{array}$ & $\begin{array}{c}(3) \\
\text { distortion }\end{array}$ \\
\hline education (secondary completion) & $-0.005 * * *$ & $-0.002 * * *$ & $-0.001 * *$ \\
\hline political freedom (deliberative democracy index) & & $-0.1 * * *$ & $-0.08 * * *$ \\
\hline economic freedom (Fraser index of economic freedom) & & -0.003 & 0.0008 \\
\hline agriculture reform (Prati et al.) & & & $-0.03 * *$ \\
\hline trade reform (Prati et al.) & & & -0.002 \\
\hline network reform (Prati et al.) & & & $0.03 * * *$ \\
\hline bank reform (Prati et al.) & & & $-0.09 * * *$ \\
\hline capital market reform (Prati et al.) & & & $0.03 * *$ \\
\hline Observations & 1,861 & 630 & 332 \\
\hline Adjusted R-squared & 0.846 & 0.912 & 0.928 \\
\hline Country FE & Yes & Yes & Yes \\
\hline
\end{tabular}

\section{Appendix I. Tables}

Table 4. Advanced Economies: Distortion

\begin{tabular}{|c|c|c|c|}
\hline VARIABLES & $\begin{array}{c}(1) \\
\text { distortion } \\
\end{array}$ & $\begin{array}{c}(2) \\
\text { distortion } \\
\end{array}$ & $\begin{array}{c}(3) \\
\text { distortion }\end{array}$ \\
\hline education (secondary completion) & $-0.004 * * *$ & -0.0002 & 0.0002 \\
\hline political freedom (deliberative democracy index) & & $-0.1 * * *$ & $-0.10 * * *$ \\
\hline economic freedom (Fraser index of economic freedom) & & $-0.02 * * *$ & $-0.01 *$ \\
\hline agriculture reform (Prati et al.) & & & 0.02 \\
\hline trade reform (Prati et al.) & & & 0.02 \\
\hline network reform (Prati et al.) & & & $0.03 * *$ \\
\hline bank reform (Prati et al.) & & & -0.03 \\
\hline capital market reform (Prati et al.) & & & -0.02 \\
\hline Observations & 593 & 183 & 107 \\
\hline Adjusted R-squared & 0.617 & 0.794 & 0.853 \\
\hline Country FE & Yes & Yes & Yes \\
\hline
\end{tabular}




\section{Appendix I. Tables}

Table 5. Emerging and Developing Countries: Distortion

\begin{tabular}{lccc}
\hline & $(1)$ & $(2)$ & $(3)$ \\
VARIABLES & distortion & distortion & distortion \\
\hline & & & \\
education (secondary completion) & $-0.006^{* * *}$ & $-0.003^{* * *}$ & $-0.003^{* * *}$ \\
political freedom (deliberative democracy index) & & $-0.09^{* * *}$ & $-0.08^{* * *}$ \\
economic freedom (Fraser index of economic freedom) & & -0.0005 & 0.004 \\
agriculture reform (Prati et al.) & & $-0.04^{* * *}$ \\
trade reform (Prati et al.) & & -0.003 \\
network reform (Prati et al.) & & $0.04^{* *}$ \\
bank reform (Prati et al.) & & $-0.1^{* * *}$ \\
capital market reform (Prati et al.) & & $0.08^{* * *}$ \\
& & & \\
Observations & 1,268 & 447 & 225 \\
Adjusted R-squared & 0.795 & 0.876 & 0.881 \\
Country FE & Yes & Yes & Yes \\
\hline \multicolumn{2}{c}{} & &
\end{tabular}

\section{Appendix I. Tables}

Table 6. Sub-Saharan Africa: Distortion

\begin{tabular}{lccc}
\hline & $(1)$ & $(2)$ & $(3)$ \\
VARIABLES & distortion & distortion & distortion \\
\hline education (secondary completion) & & & \\
political freedom (deliberative democracy index) & $-0.006^{* * *}$ & $-0.002^{* * *}$ & $-0.004^{*}$ \\
economic freedom (Fraser index of economic freedom) & & $-0.1^{* * *}$ & -0.0005 \\
agriculture reform (Prati et al.) & $-0.01^{*}$ & -0.02 \\
trade reform (Prati et al.) & & $-0.2^{* * *}$ \\
network reform (Prati et al.) & & $-0.2^{* * *}$ \\
bank reform (Prati et al.) & & 0.09 \\
capital market reform (Prati et al.) & & 0.10 \\
& & & 0.09 \\
Observations & & & 420 \\
Adjusted R-squared & 420 & 150 & 44 \\
Country FE & 0.885 & 0.902 & 0.936 \\
& Yes & Yes & Yes \\
\hline \multicolumn{2}{c}{} & &
\end{tabular}




\section{Appendix I. Tables}

Table 7. Emerging and Developing Countries: Agricultural Sector Distortion

\begin{tabular}{lccc}
\hline & $(1)$ & $(2)$ & $(3)$ \\
VARIABLES & distortion & distortion & distortion \\
\hline & & & \\
education (secondary completion) & $-0.007^{* * *}$ & $-0.003^{* * *}$ & $-0.003^{* * *}$ \\
political freedom (deliberative democracy index) & & $-0.1^{* * *}$ & $-0.008^{* * *}$ \\
economic freedom (Fraser index of economic freedom) & & $-0.0006^{*}$ & 0.007 \\
agriculture reform (Prati et al.) & & -0.02 \\
trade reform (Prati et al.) & & -0.005 \\
network reform (Prati et al.) & & -0.007 \\
bank reform (Prati et al.) & & $-0.1^{* * *}$ \\
capital market reform (Prati et al.) & & $0.06^{* * *}$ \\
& & & \\
Observations & 1,268 & 447 & 225 \\
Adjusted R-squared & 0.848 & 0.917 & 0.927 \\
Country FE & Yes & Yes & Yes \\
\hline & $* * * \mathrm{p}<0.01, * * \mathrm{p}<0.05, * \mathrm{p}<0.1$ & \multicolumn{2}{c}{}
\end{tabular}

\section{Appendix I. Tables}

Table 8. Emerging and Developing Countries: Manufacturing Sector Distortion

\begin{tabular}{|c|c|c|c|}
\hline VARIABLES & $\begin{array}{c}1) \\
\text { distortion }\end{array}$ & $\begin{array}{c}(2) \\
\text { distortion }\end{array}$ & $\begin{array}{c}\text { (3) } \\
\text { distortion }\end{array}$ \\
\hline education (secondary completion) & $0.0006 * * *$ & $0.0006 * * *$ & 0.0006 \\
\hline political freedom (deliberative democracy index) & & 0.007 & -0.001 \\
\hline economic freedom (Fraser index of economic freedom) & & $-0.004 * * *$ & $-0.008 * * *$ \\
\hline agriculture reform (Prati et al.) & & & 0.008 \\
\hline trade reform (Prati et al.) & & & 0.03 \\
\hline network reform (Prati et al.) & & & $-0.02 * *$ \\
\hline bank reform (Prati et al.) & & & 0.008 \\
\hline capital market reform (Prati et al.) & & & 0.02 \\
\hline Observations & 1,268 & 447 & 225 \\
\hline Adjusted R-squared & 0.690 & 0.833 & 0.837 \\
\hline Country FE & Yes & Yes & Yes \\
\hline
\end{tabular}




\section{Appendix I. Tables}

Table 9. Sub-Saharan Africa: Agricultural Sector Distortion

\begin{tabular}{|c|c|c|c|}
\hline VARIABLES & $\begin{array}{c}(1) \\
\text { Distortion } \\
\end{array}$ & $\begin{array}{c}(2) \\
\text { distortion } \\
\end{array}$ & $\begin{array}{c}(3) \\
\text { distortion }\end{array}$ \\
\hline $\begin{array}{l}\text { education (secondary completion) } \\
\text { political freedom (deliberative democracy index) } \\
\text { economic freedom (Fraser index of economic freedom) } \\
\text { agriculture reform (Prati et al.) } \\
\text { trade reform (Prati et al.) } \\
\text { network reform (Prati et al.) } \\
\text { bank reform (Prati et al.) } \\
\text { capital market reform (Prati et al.) }\end{array}$ & $-0.006 * * *$ & $\begin{array}{c}-0.002 * * * \\
-0.2 * * * \\
-0.004\end{array}$ & $\begin{array}{c}-0.006 * * \\
0.007 \\
-0.02 \\
-0.2 * * * \\
-0.2 * * * \\
0.08 \\
0.1 \\
0.09\end{array}$ \\
\hline $\begin{array}{l}\text { Observations } \\
\text { Adjusted R-squared } \\
\text { Country FE }\end{array}$ & $\begin{array}{l}420 \\
0.892 \\
\text { Yes }\end{array}$ & $\begin{array}{c}150 \\
0.927 \\
\text { Yes }\end{array}$ & $\begin{array}{c}44 \\
0.944 \\
\text { Yes }\end{array}$ \\
\hline
\end{tabular}

\section{Appendix I. Tables}

Table 10. Sub-Saharan Africa: Manufacturing Sector Distortion

\begin{tabular}{|c|c|c|c|}
\hline VARIABLES & $\begin{array}{c}(1) \\
\text { distortion }\end{array}$ & $\begin{array}{c}(2) \\
\text { distortion } \\
\end{array}$ & $\begin{array}{c}(3) \\
\text { distortion } \\
\end{array}$ \\
\hline education (secondary completion) & $-0.0009 * * *$ & -0.0003 & -0.002 \\
\hline political freedom (deliberative democracy index) & & 0.001 & 0.01 \\
\hline economic freedom (Fraser index of economic freedom) & & $-0.008 * * *$ & $-0.02 * *$ \\
\hline agriculture reform (Prati et al.) & & & $-0.01 * * *$ \\
\hline trade reform (Prati et al.) & & & $-0.08 * * *$ \\
\hline network reform (Prati et al.) & & & 0.04 \\
\hline bank reform (Prati et al.) & & & $0.1 * * *$ \\
\hline capital market reform (Prati et al.) & & & 0.01 \\
\hline Observations & 420 & 150 & 44 \\
\hline Adjusted R-squared & 0.684 & 0.808 & 0.823 \\
\hline Country FE & Yes & Yes & Yes \\
\hline
\end{tabular}




\section{Appendix II. Data}

Our index is based on the sectoral data on value-added and employment constructed by Timmer et al. (2014). A variant of the 10-sector database is Africa sector database by Vries et al. (2015). ${ }^{1}$ Both of these databases have excellent documentations, so we do not repeat the details. Instead, we note several data cleaning processes in this paper. First, we drop West Germany whose data spans from 1968 to 1991. Second, since data on government sector employment are not available for Zambia, we exclude value-added of the government sector from the data, and adjust the total value-added accordingly. We use real value added data since it covers longer periods than the nominal for most countries.

The data on real GDP are taken from Penn World Table 9.0 by Freenstra et al. (2015).

Our regression analysis adopts the independent variables used in Dabla-Norris et al. (2013a and 2013b) and Prati et al. (2012). In particular, our education variable is from Barro and Lee (2013), which is one of many useful variables collected by Stefan et al. (2016). The education variable is the percentage of population above 25 years old who completed secondary education. Our political freedom variable, originally constructed by Heritage Foundation (2015), is also one of the datasets in Stefan (2016). It is the deliberative democracy index, based on questionnaires sent to anonymous country experts asking "To what extent is the ideal of deliberative democracy achieved?" Our economic freedom variable comes from Gwartney et al. (2015). It is a weighted sum of 42 variables that try to capture 5 components. ([1] size of government; [2] legal system and security of property rights; [3] sound money; [4] freedom to trade internationally; [5] regulation, including labor market regulation.) Economic reform variables are from Prati et al. (2012). Agriculture reform is higher if a larger degree of agriculture-related structural reforms selected by the authors has been conducted. Network reform refers to electricity market reforms such as unbundling of generation, transmission and distribution. The bank reform variable is based on interest rate controls, credit controls and so on. Capital market reform is about regulation of securities markets including policies to encourage the development of bond and equity markets. For further details, see the Appendix of Prati et al. (2012).

\footnotetext{
${ }^{1}$ A caveat for developing countries' employment data is that there are no reliable or regular labor market statistics. Furthermore, a large percentage of workers are either unemployed or employed informally. For these reasons, the results using the employment data must be interpreted with caution.
} 


\section{Appendix III. The Model}

This section provides a frictionless general equilibrium model in which sectoral productivity is equalized among all the sectors. In particular, we emphasize that the average productivity equalization across industries can be compatible with the decreasing returns to scale production technology in individual heterogeneous firms. The model extends Kanbur (1979) by introducing multiple sectors.

Let us assume that there are $\mathrm{S}$ sectors. Each agent $i \in[0,1]$ can choose which sector to enter and the occupation, i.e., whether to become an entrepreneur or a worker. If agent $i$ chooses to enter sector $s$ as a worker, she works for wage $w_{s}$. If agent $i$ chooses to enter sector $s$ as an entrepreneur, she draws a lottery on the productivity of her firm $z_{s i} \sim G_{s}$. With productivity $z_{s i}$, she runs a company by determining the number of employees $h$.

$$
\left[\pi_{s i}, h_{s i}\right]=\max _{h} p_{s} z_{s i} h^{\alpha}-w_{s} h
$$

where $\pi_{s i}$ and $h_{s i}$ are the profit and the number of employees of firm $i$, and $\alpha_{s}$ is the share of sales paid to employees. Profit $\pi_{s i}$ is the income of agent $i$, while the income for workers is $w_{s}$. Given individual income, denoted by $e_{i}$, each agent solves the utility maximization problem

$$
\left[v\left(p, e_{i}\right), c_{i}\right]=\max _{\left\{c_{s}\right\}} \prod_{s=1}^{S} c_{s}^{\gamma_{s}} \text { s.t. } \sum_{s=1}^{S} p_{s} c_{s}=e_{i}
$$

where $v$ and $c_{i}=\left\{c_{i s}\right\}_{s}$ are the indirect utility function and the consumption, respectively; and the preference parameter $\gamma_{s}$ represents the expenditure share of product $s$. We assume

$$
\sum_{s=1}^{S} \gamma_{s}=1
$$

so that $\gamma_{s}$ is the expenditure share. Since all agents choose their occupations, income has to satisfy the free entry condition

$$
E v\left(p, \pi_{s}\right)=v\left(p, w_{s}\right)=v\left(p, w_{s^{\prime}}\right), \quad \forall s, s^{\prime}
$$

where expectation is with respect to $z_{s} \sim G_{s}$ for each sector s. Finally, the set of prices $\left(p_{s}, w_{s}\right)$, the number of people engaged in sectors $n_{s}$ and the fraction of entrepreneurs among them $\phi_{s}$ have to be consistent with the market clearing conditions.

$$
\int h_{s i} d i=\left(1-\phi_{s}\right) n_{s}, \quad \sum_{s=1}^{S} n_{s}=1, \quad Y_{s}:=\int y_{s i} d i=\int c_{s i} d i .
$$


In summary, we are interested in the following equilibrium:

Definition: The set of prices $\left(p_{s}, w_{s}\right)$, quantities $\left(c_{s i}, y_{s i}, h_{s i}\right)$ and the number of people $\left(n_{s}, \phi_{s}\right)$ constitutes an equilibrium if

1. Given prices $\left(p_{s}, w_{s}\right)$, each firm solves (A1).

2. Given prices $\left(p_{s}, w_{s}\right)$, each agent solves (A2).

3. Free entry (A3) and market clearing conditions (A4) are satisfied.

This general equilibrium model has a closed form solution. To see this, note that the firm's problem can be solved as follows:

$$
h_{s i}=\left(\frac{p_{s} z_{s i} \alpha_{s}}{w_{s}}\right)^{\frac{1}{1-\alpha_{s}}}, \pi_{s i}=p_{s}\left(1-\alpha_{s}\right) \alpha_{s}^{\frac{\alpha_{s}}{1-\alpha_{s}}} z_{s i}^{\frac{1}{1-\alpha_{s}}}\left(\frac{w_{s}}{p_{s}}\right)^{-\frac{\alpha_{s}}{1-\alpha_{s}}}
$$

The free entry condition implies

$$
\frac{w_{s}}{p_{s}}=\left(1-\alpha_{s}\right)^{1-\alpha_{s}} \alpha_{s}^{\alpha_{s}}\left(E z_{s}^{\frac{1}{1-\alpha_{s}}}\right)^{1-\alpha_{s}}, \quad \phi_{s}=1-\alpha_{s}
$$

The production function can be aggregated into

$$
Y_{s}=\left(E z_{s}^{\frac{1}{1-\alpha_{s}}}\right)^{1-\alpha_{s}}\left(1-\alpha_{s}\right)^{1-\alpha_{s}} \alpha_{s}^{\alpha_{s}} n_{s}
$$

so that the consumer's problem and the market clearing conditions imply

$$
\gamma_{s} \frac{\sum_{s=1}^{S} p_{s} Y_{s}}{p_{s}}=Y_{s}, \quad \forall s \Rightarrow \frac{p_{s}}{p_{s^{\prime}}}=\frac{y_{s^{\prime}}}{y_{s}}, \quad n_{s}=\gamma_{s} .
$$

Hence, the equilibrium exists and is unique.

An important implication is that the sectoral productivity is equalized in equilibrium, i.e.,

$$
\frac{p_{s} Y_{s}}{n_{s}}=\frac{p_{s^{\prime}} Y_{s^{\prime}}}{n_{s^{\prime}}}, \quad \forall s, s^{\prime}
$$

To see this, substitute the equilibrium objects into the equation, or take a short cut by observing that total sales have to be distributed to both entrepreneurs and workers.

$$
n_{s} \phi_{s} E \pi_{s}+n_{s}\left(1-\phi_{s}\right) w_{s}=p_{s} Y_{s}
$$


Since entrepreneurs and workers are indifferent due to the free entry condition, $E \pi_{s}=w_{s}$; and since the free entry condition also equalizes all sectors' wage levels, $w_{s}=w_{s^{\prime}}$. Hence, sectoral productivity is the same across all sectors.

We note two assumptions embedded in the above argument. First, the indirect utility function $v$ is linear in income $e$. Hence, agents are risk neutral with respect to income. Even though this may be considered a knife-edge specification, it is not a bad approximation of occupational choice, given that the risk premium of entrepreneurship is rarely observed empirically. Second, the model does not have capital as in the standard neoclassical model. Instead, we have entrepreneurs in the model. One way to interpret this is that the owner of each firm owns one unit of firm-specific capital, so that the profit is the return on capital. 


\section{Appendix IV. Ternary Plots}

In the graphs below, the green and orange lines are employment and value-added shares, respectively. The vertices are primary, secondary and tertiary sectors clockwise.

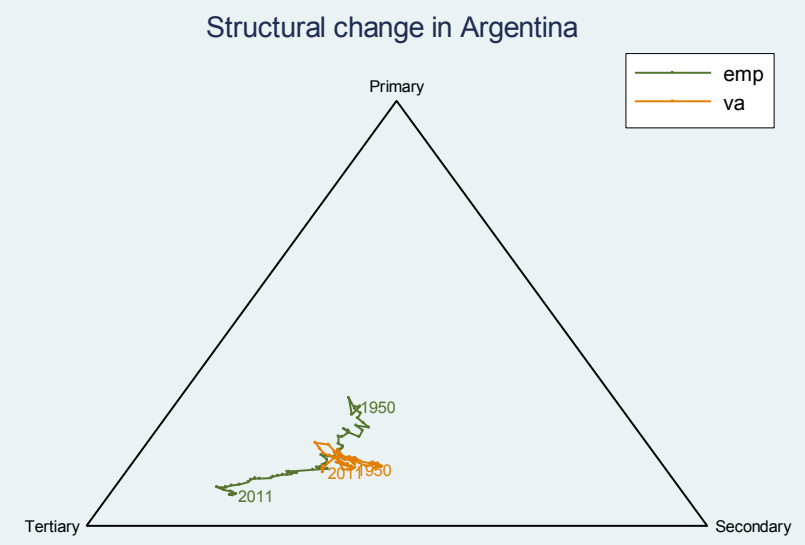

Structural change in Botswana

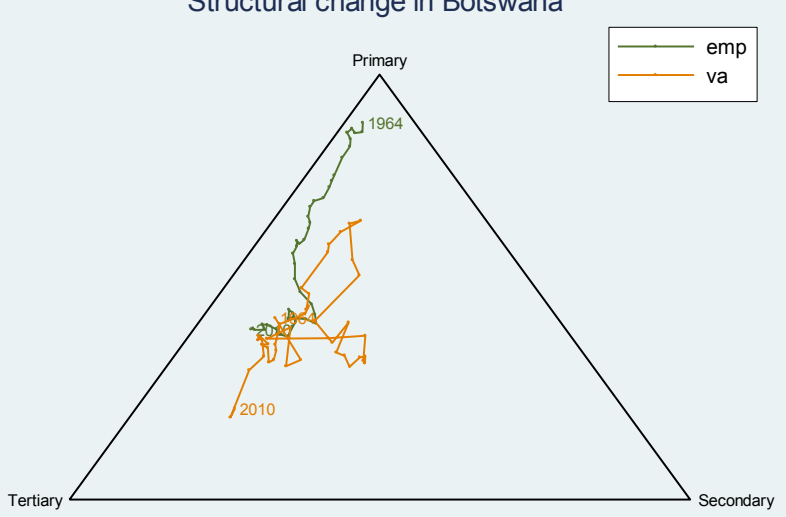

Structural change in Chile

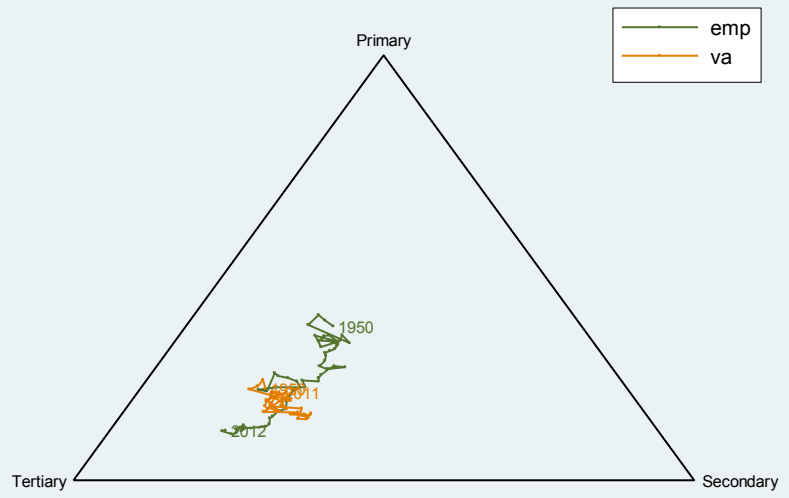

Structural change in Bolivia

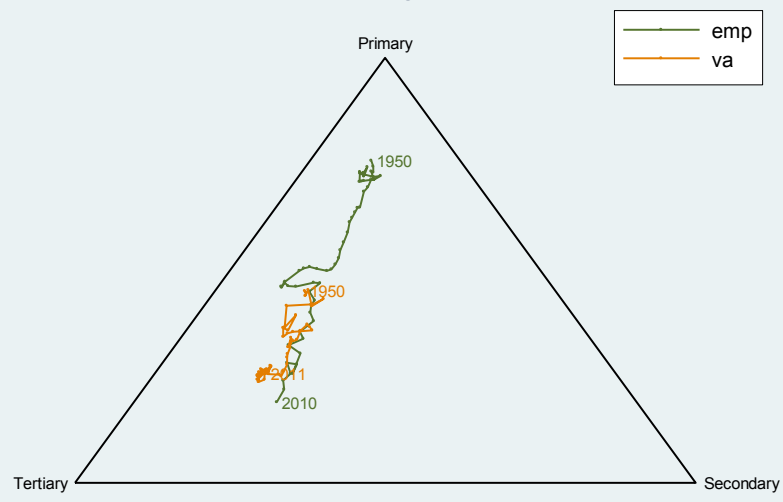

Structural change in Brazil

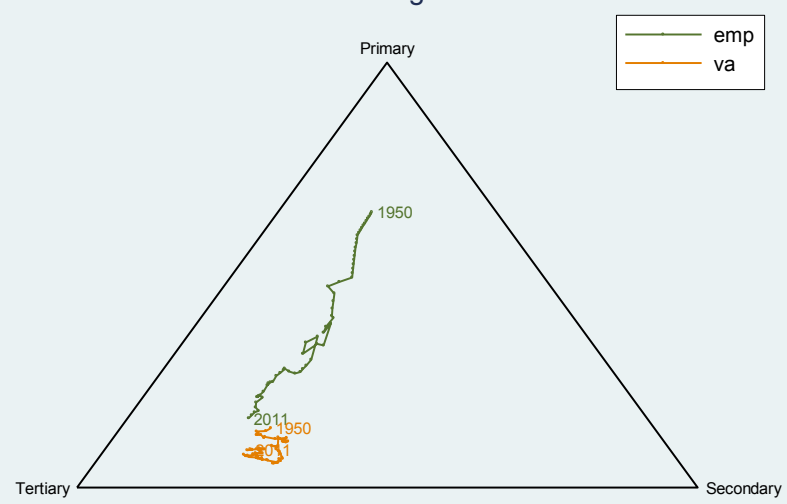

Structural change in China

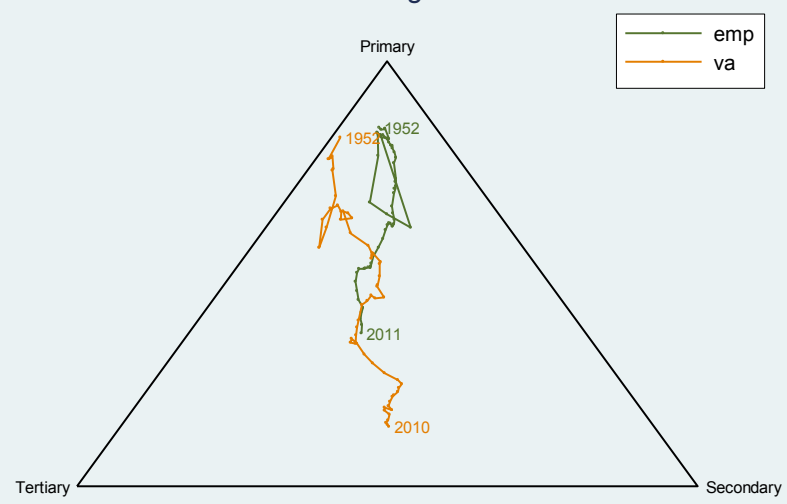




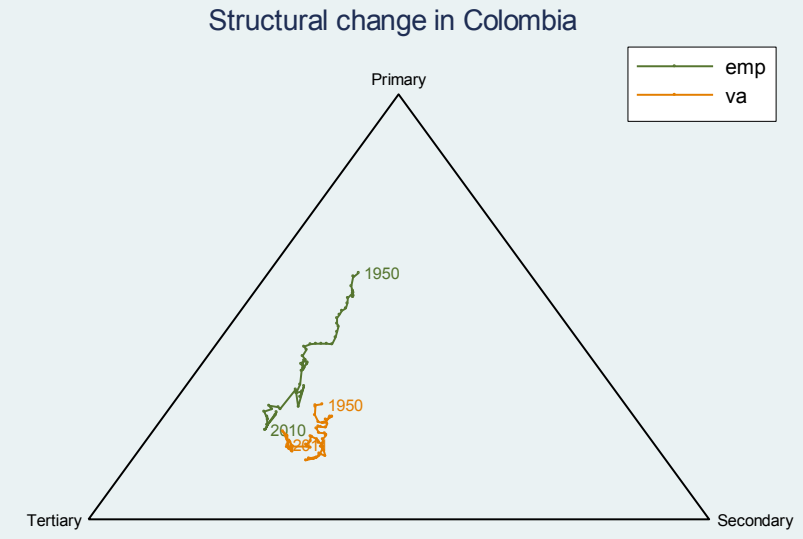

Structural change in Denmark

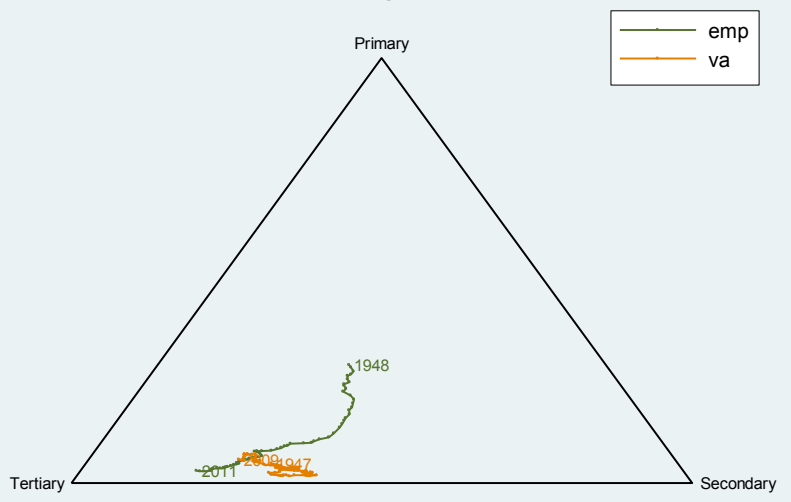

Structural change in Ethiopia

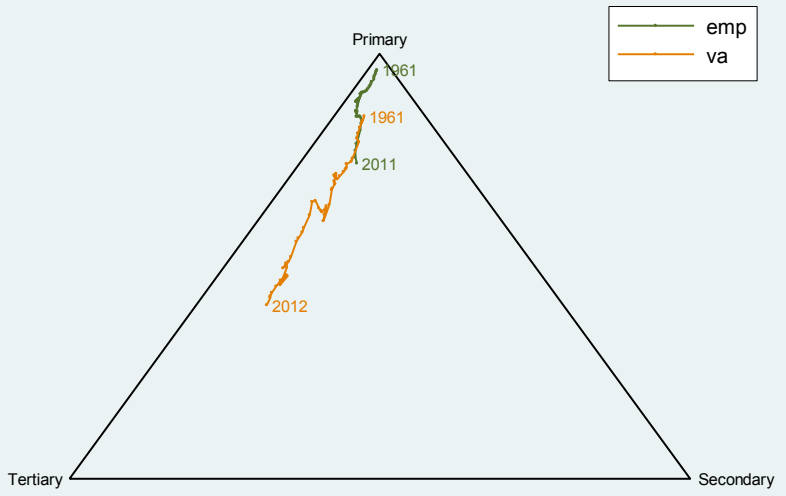

Structural change in Costa Rica

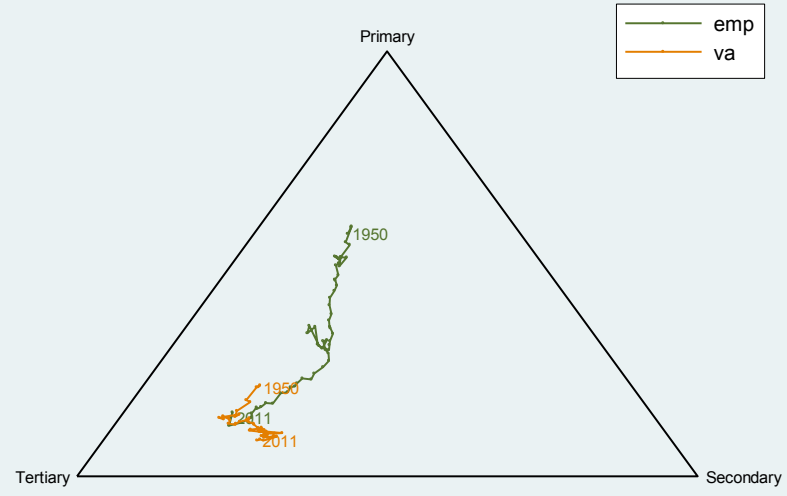

Structural change in Egypt

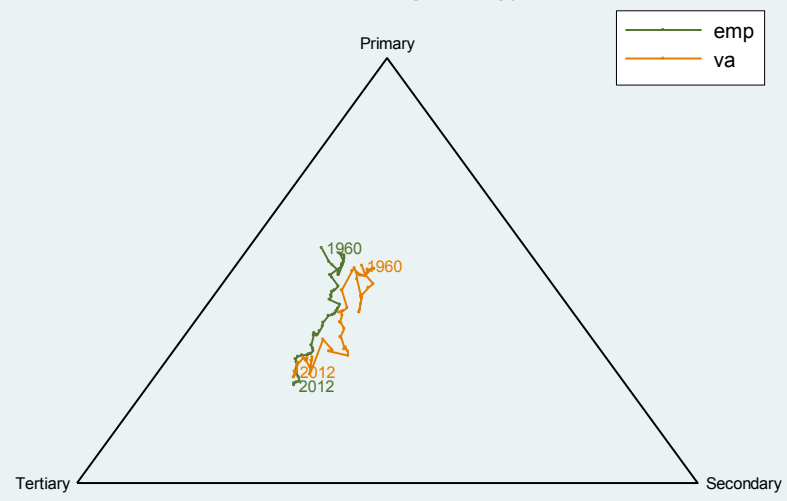

Structural change in France

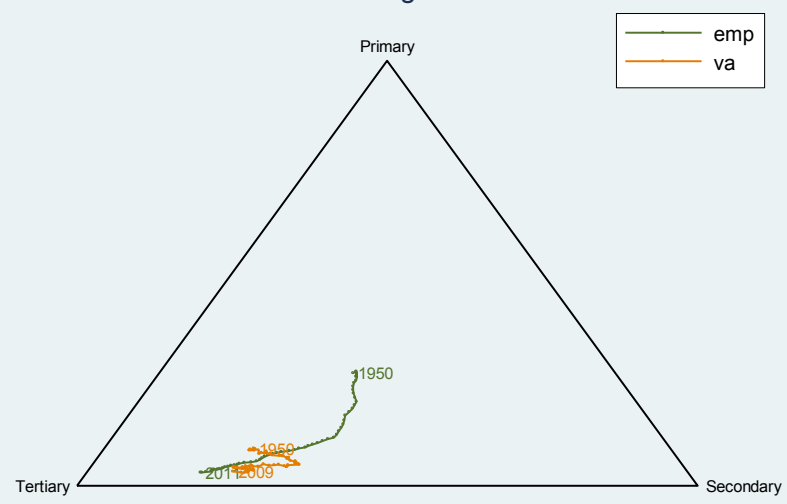




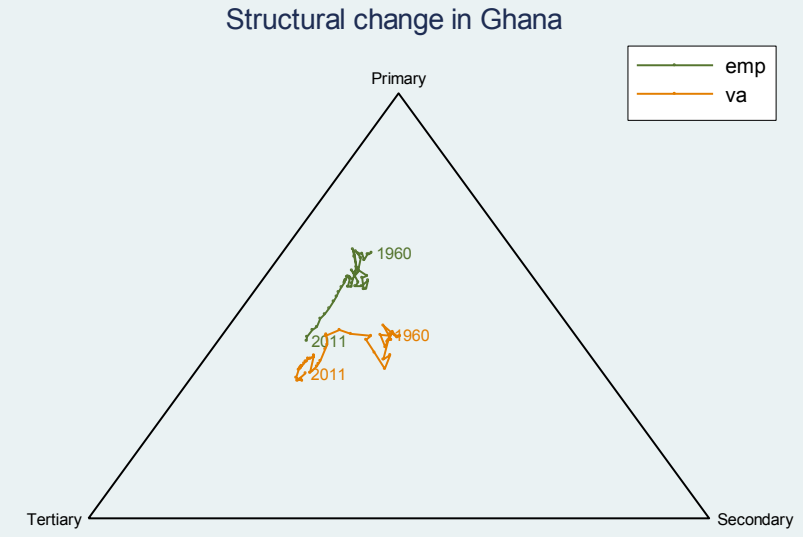

Structural change in India

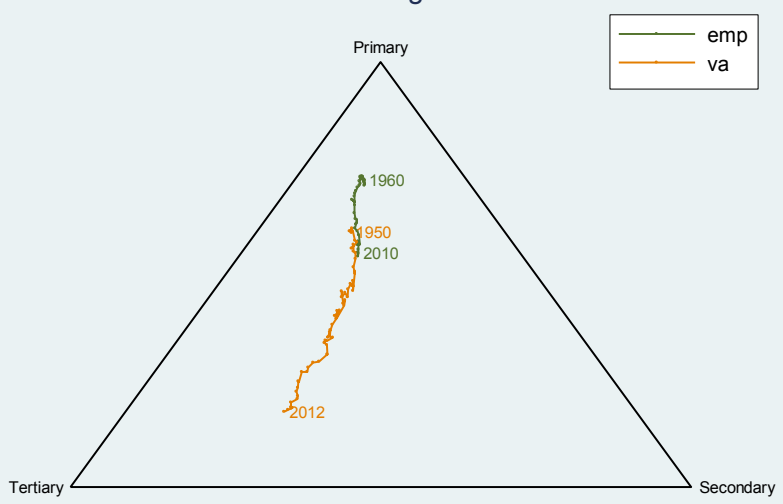

Structural change in Italy

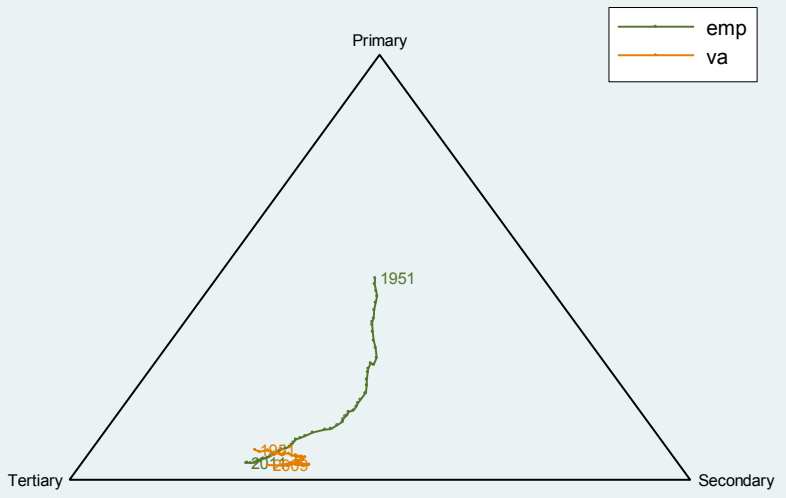

Structural change in Hong Kong SAR

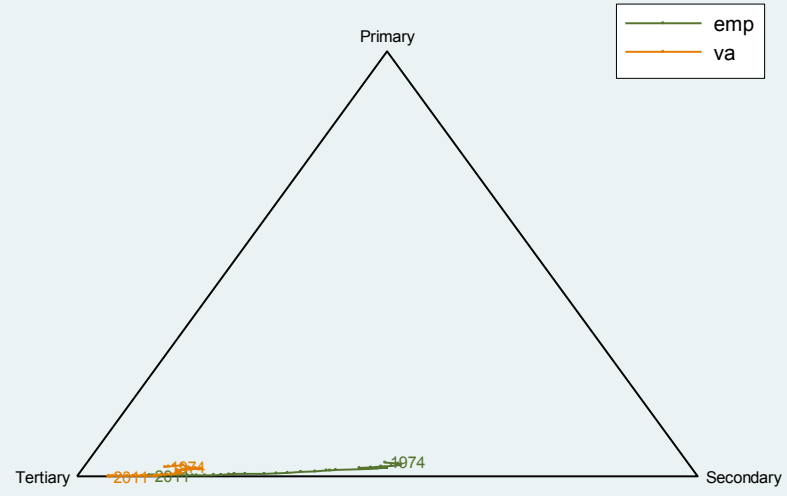

Structural change in Indonesia

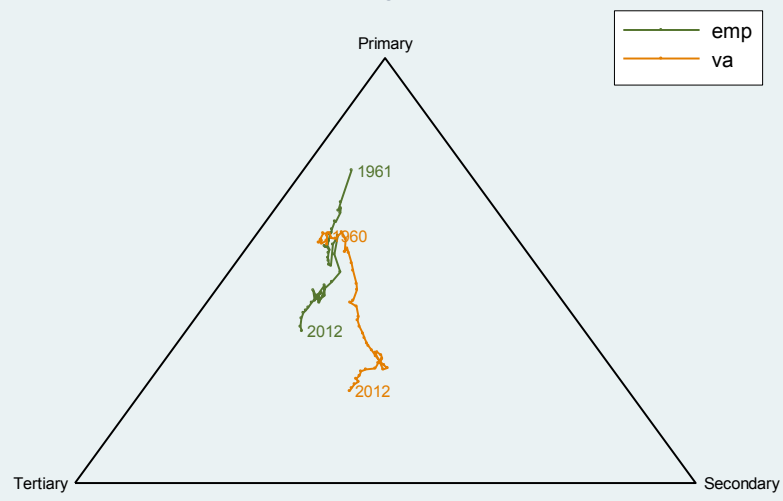

Structural change in Japan

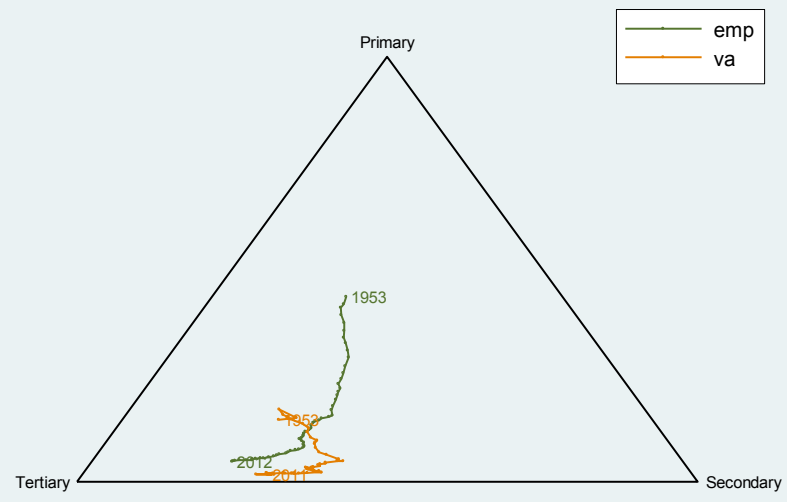



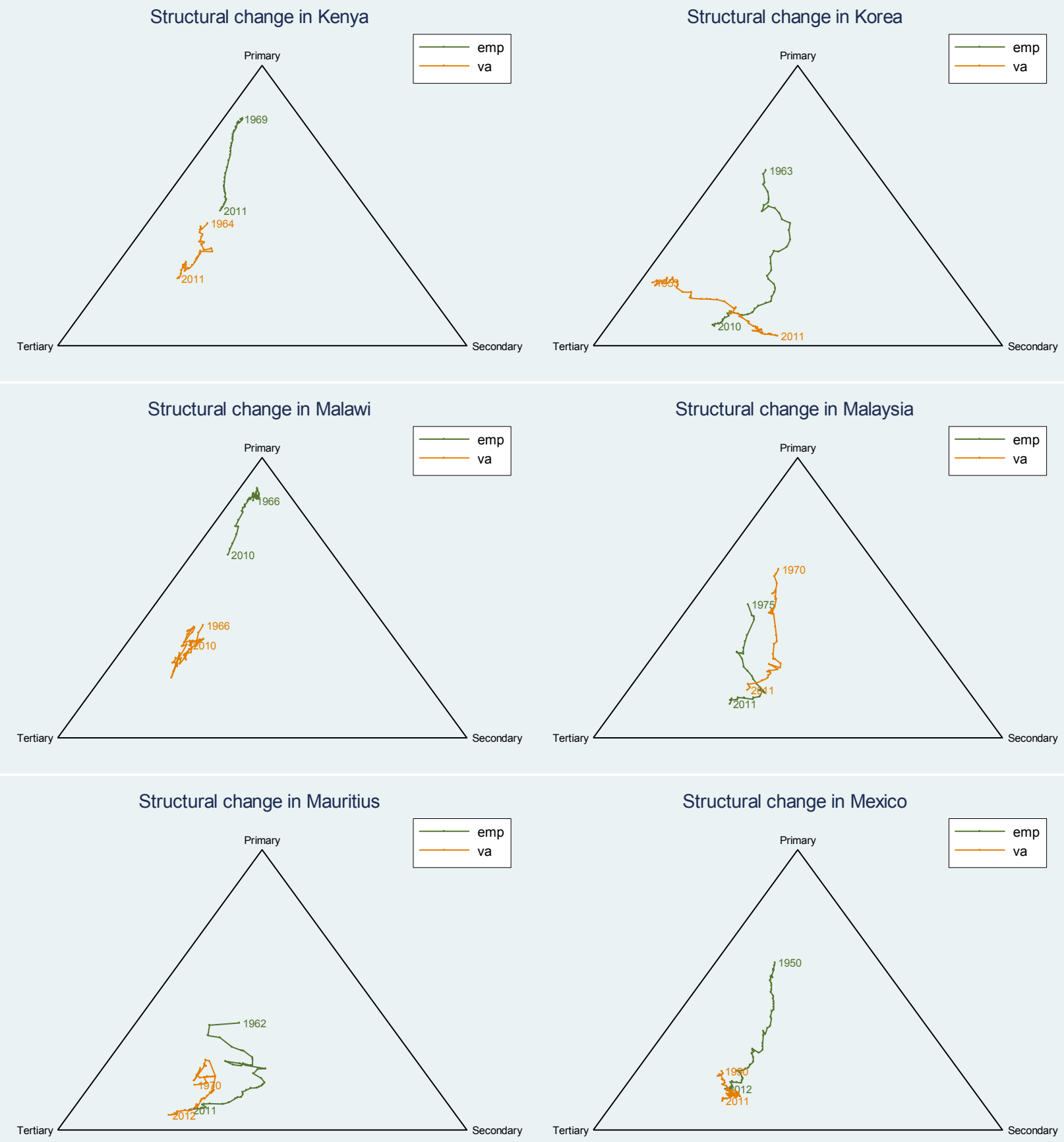


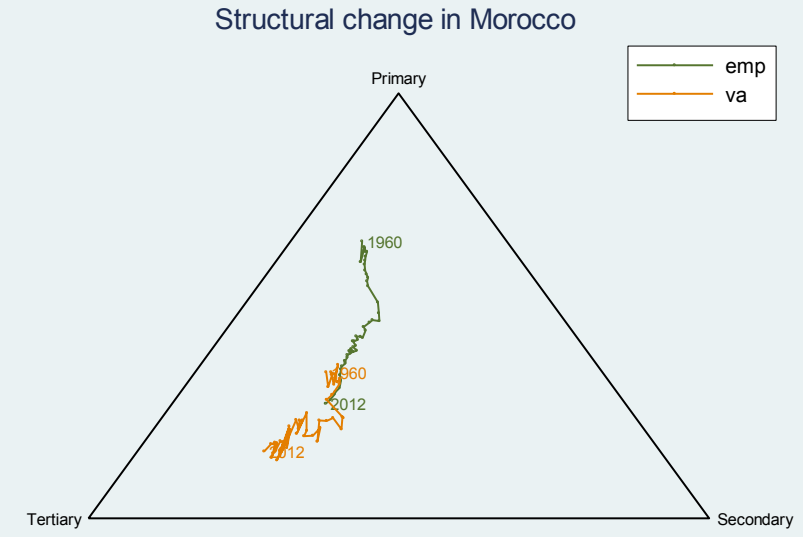

Structural change in Nigeria

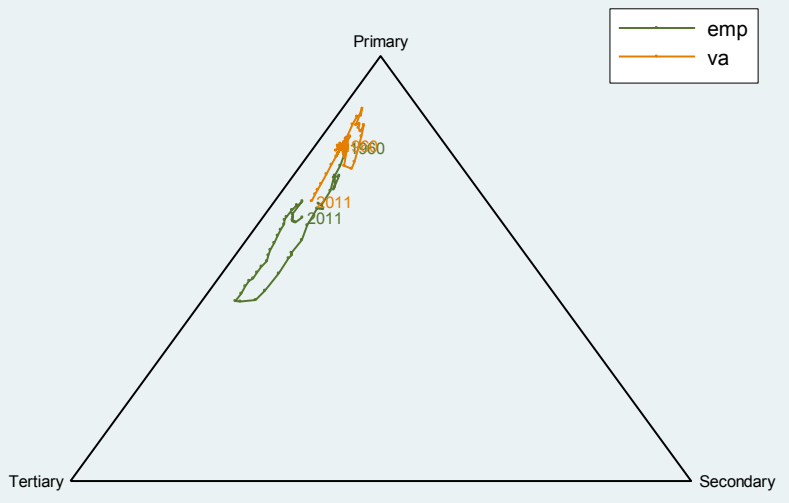

Structural change in Philippines

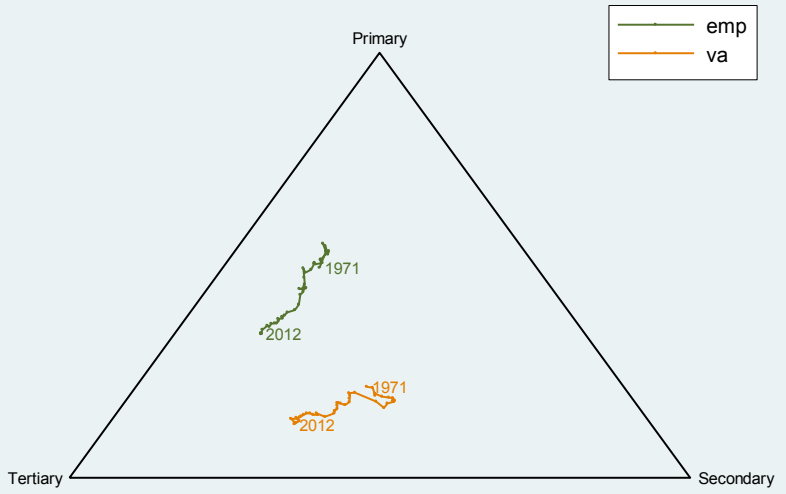

Structural change in Netherlands

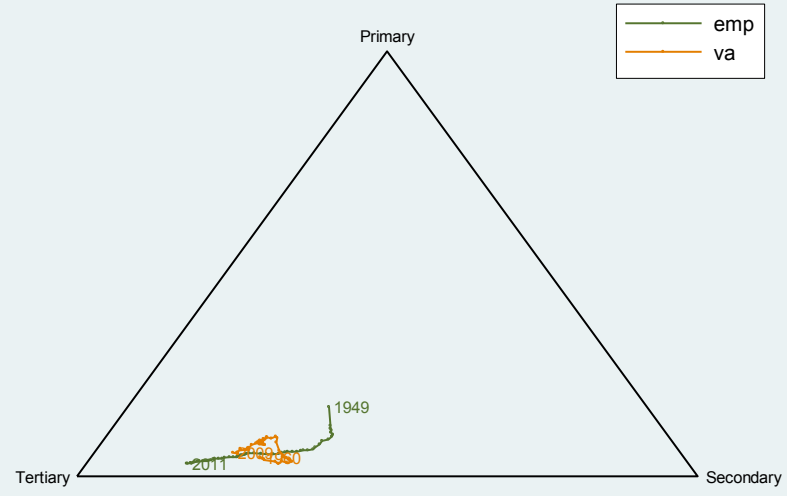

Structural change in Peru

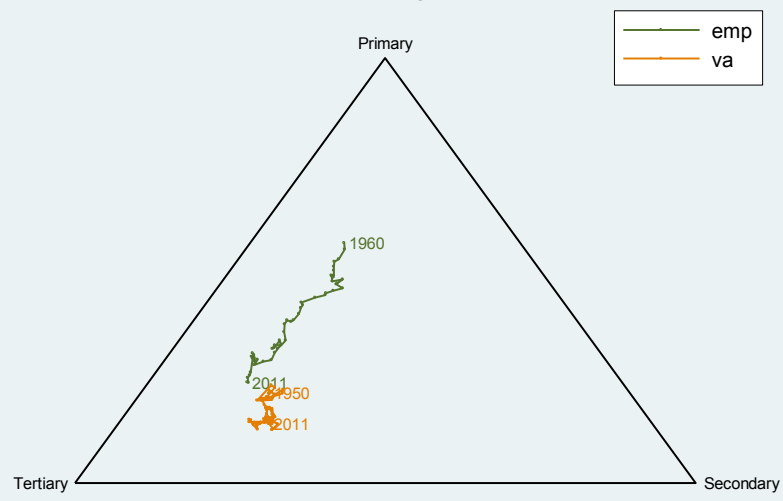

Structural change in Senegal

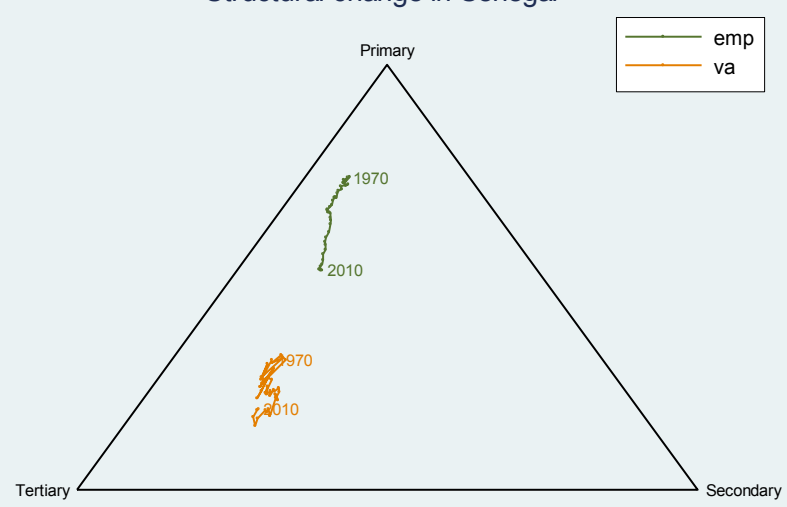




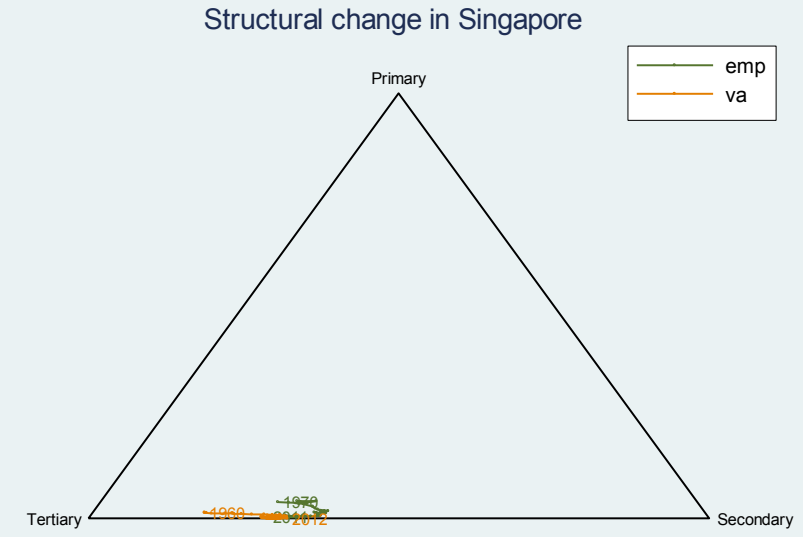

Structural change in Spain

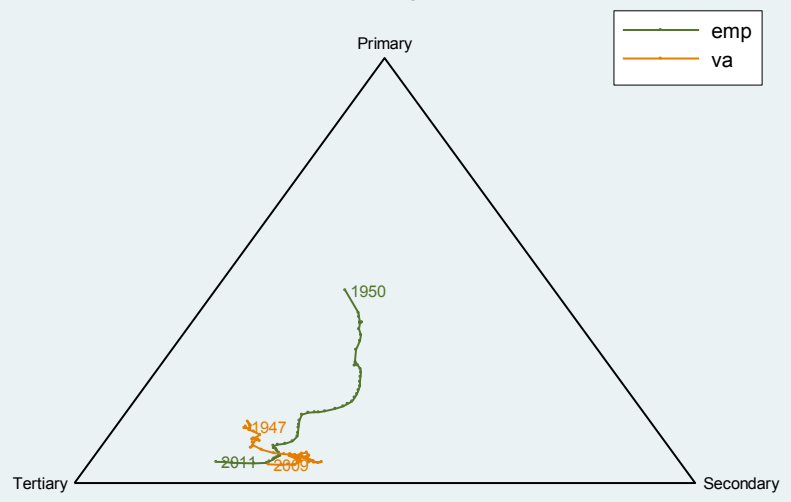

Structural change in Taiwan Province of China

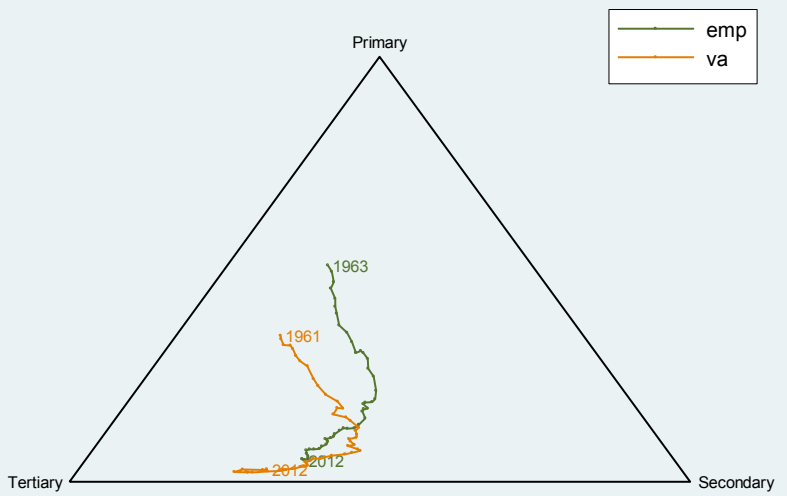

Structural change in South Africa

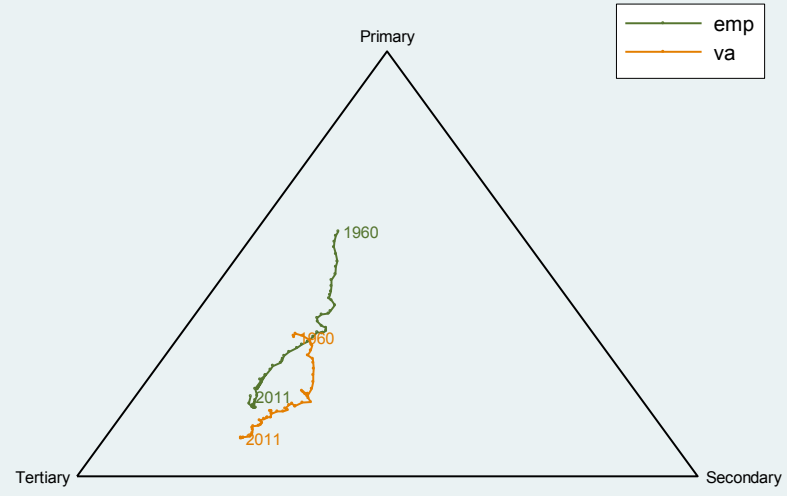

Structural change in Sweden

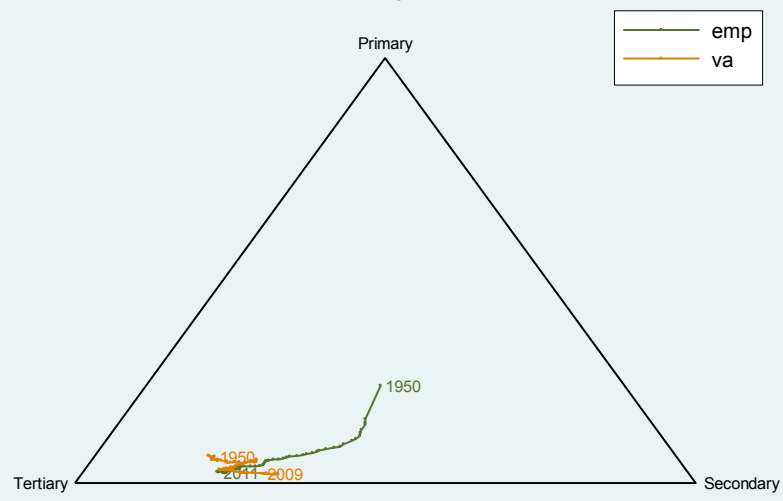

Structural change in Tanzania

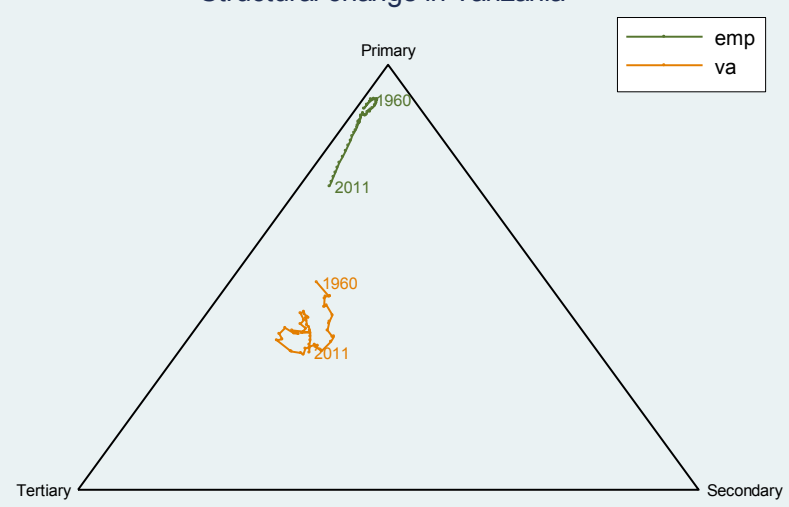




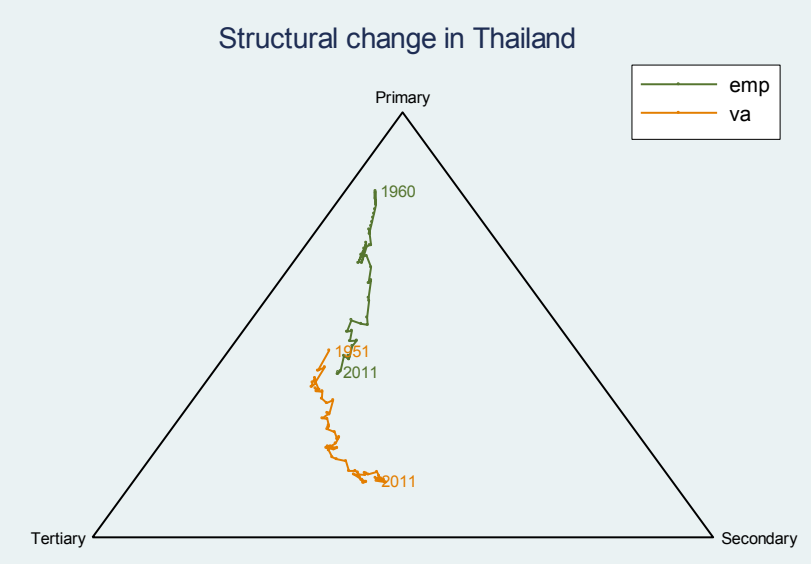

Structural change in United States

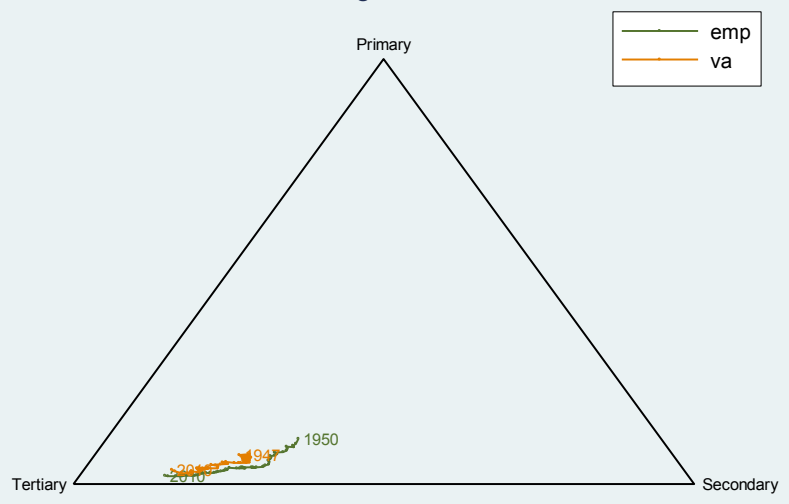

Structural change in Zambia

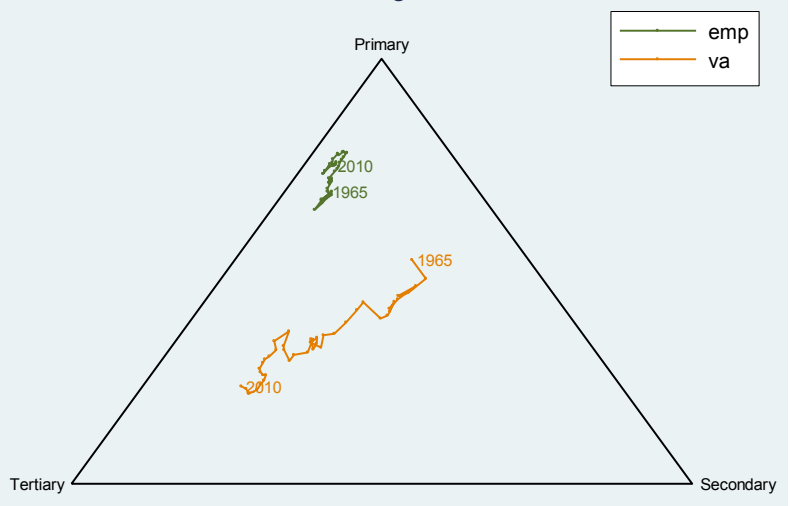

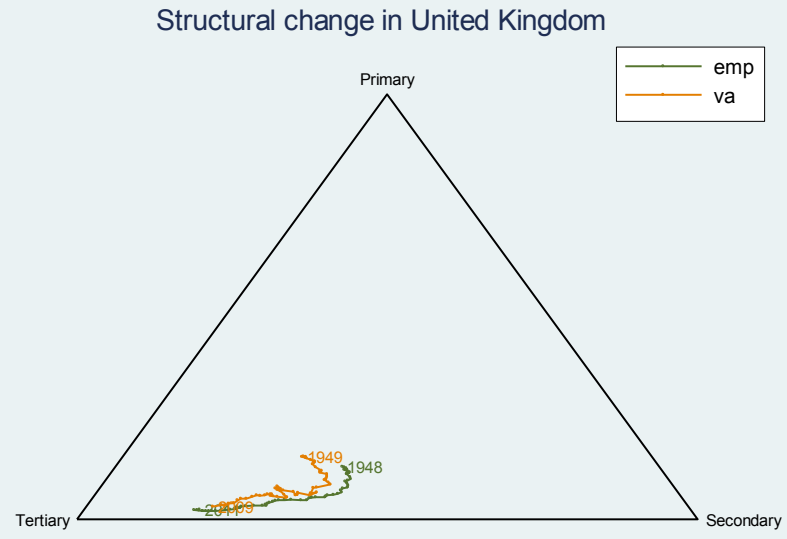

Structural change in Venezuela

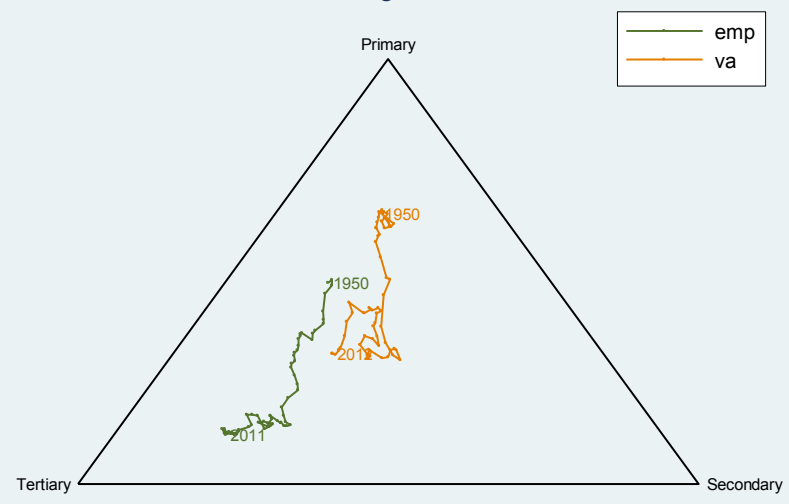




\section{Appendix V. $\left\{d, d_{i}\right\}$ Plots}

In this appendix, the graphs on the left plot log real GDP per capita against the distortion index $\mathrm{d}$. The label attached to each dot is the last two digits of the year. The graphs on the right are the same 10 sector plots of d_i.

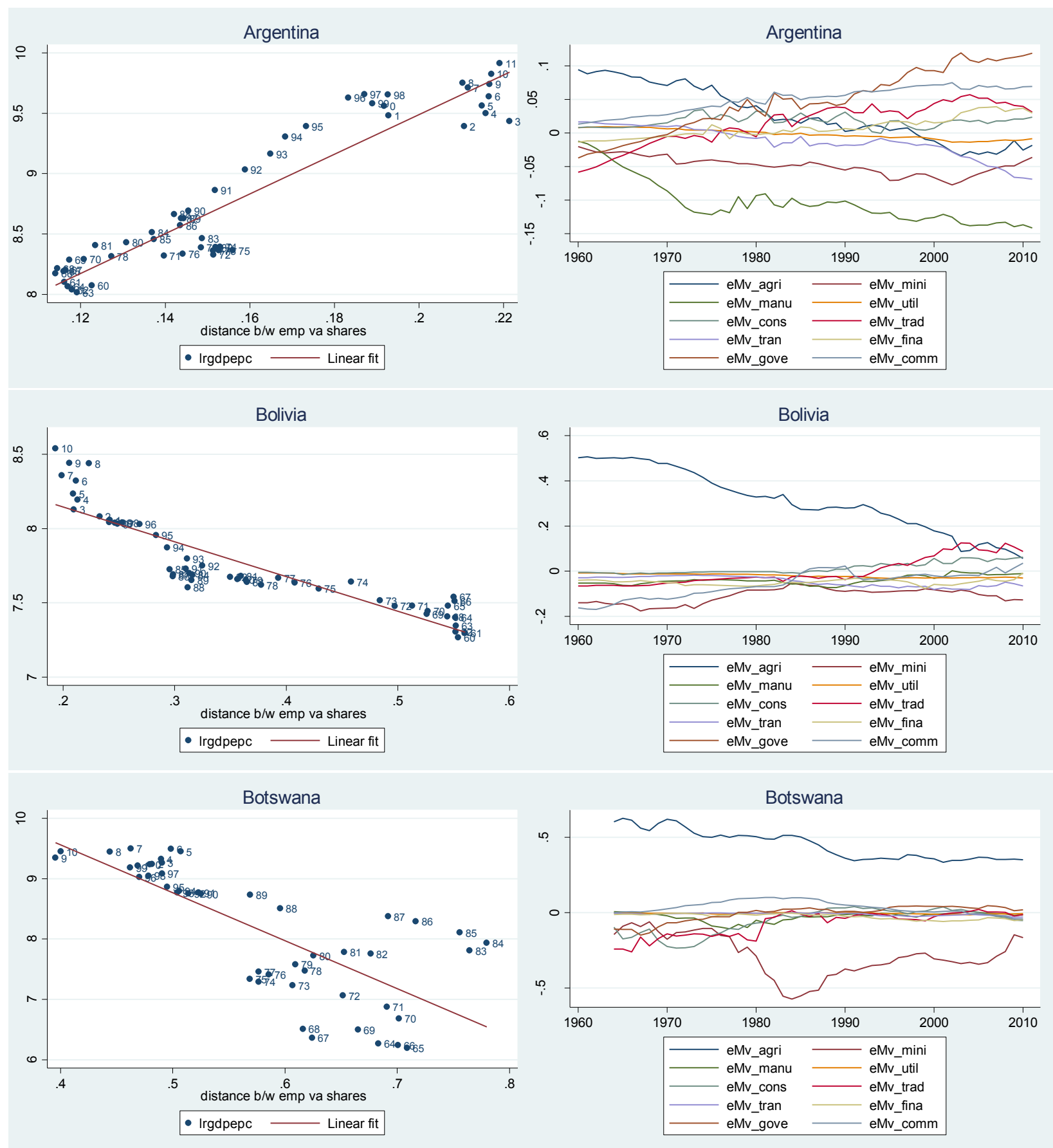



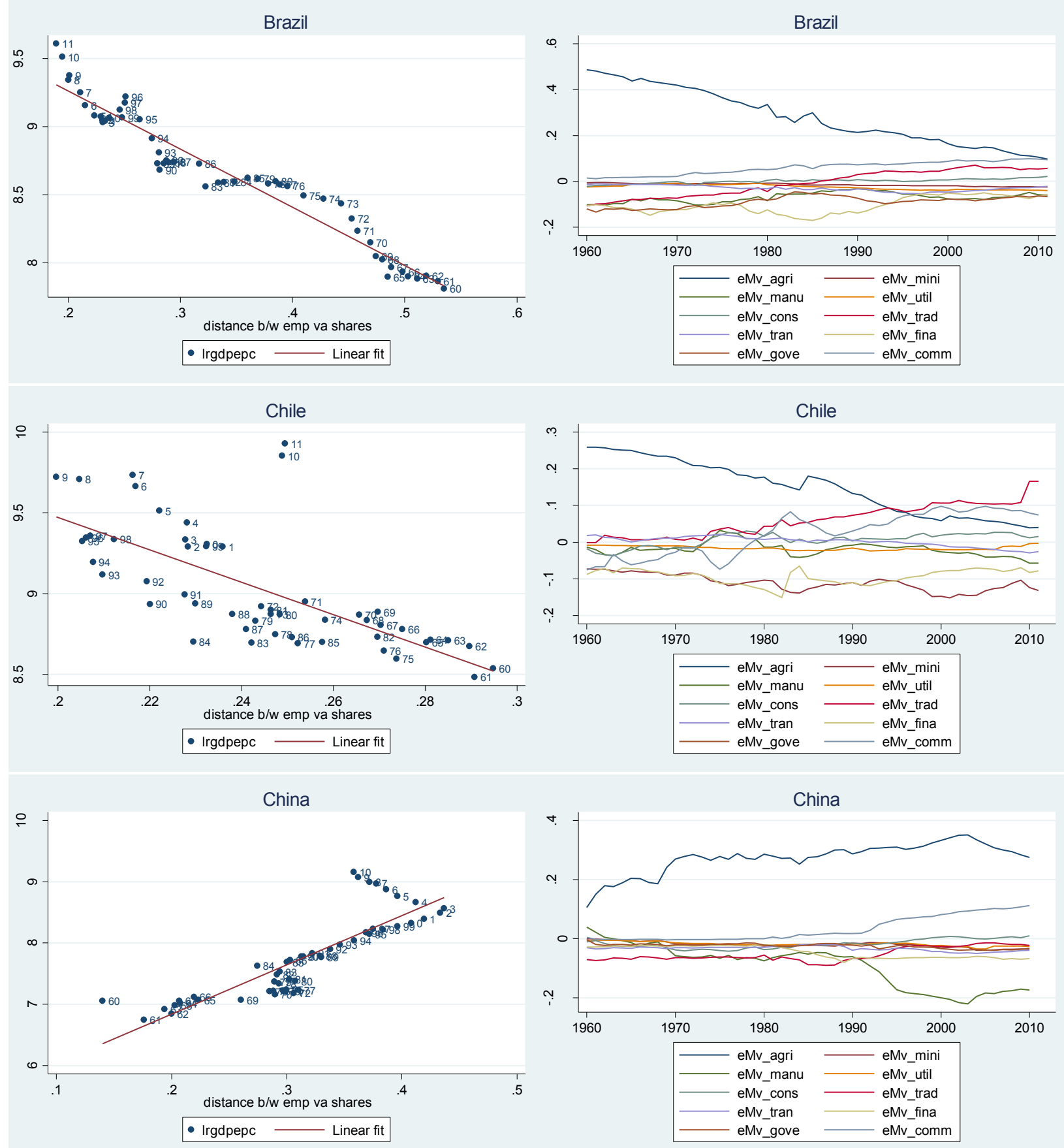

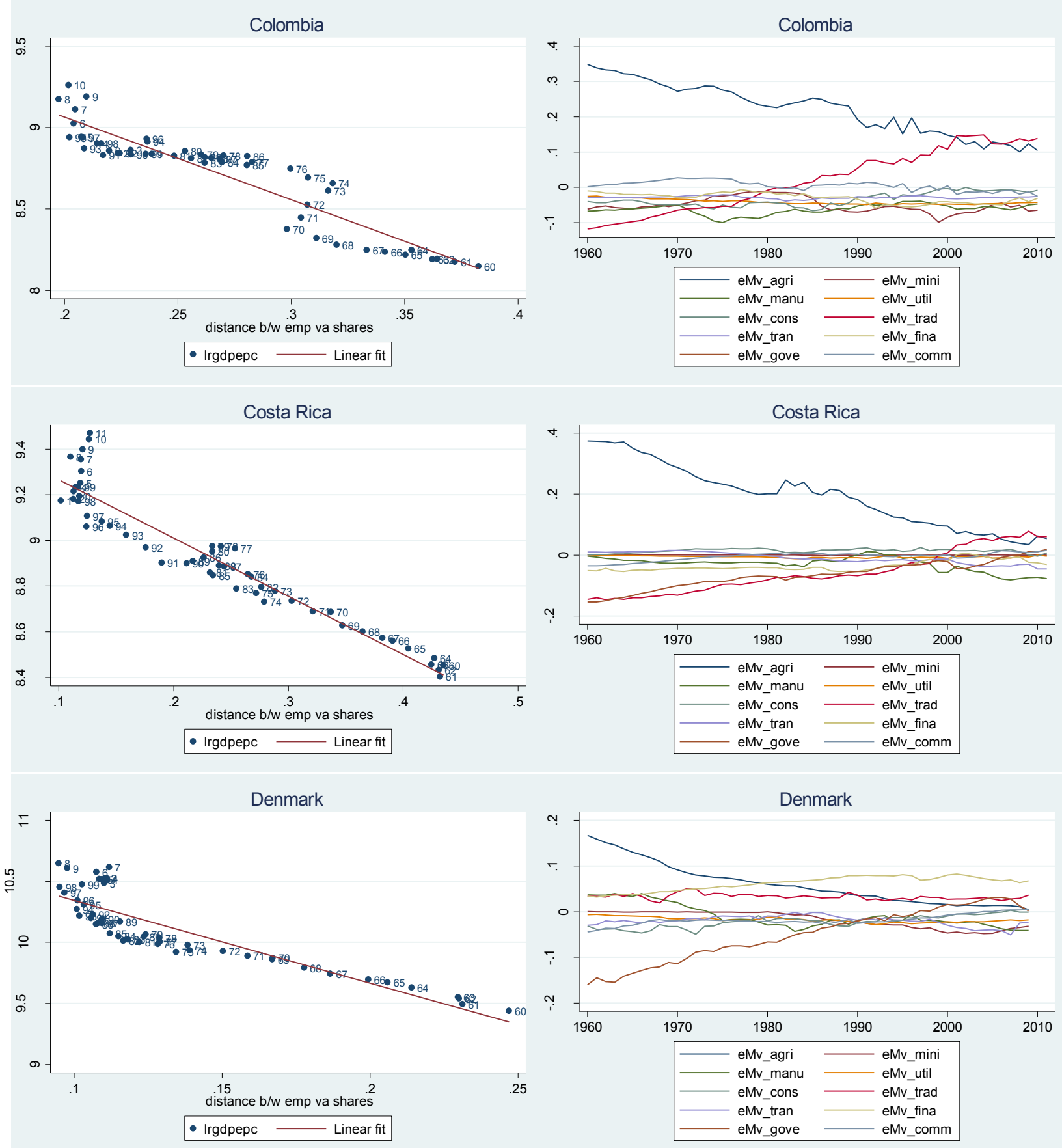


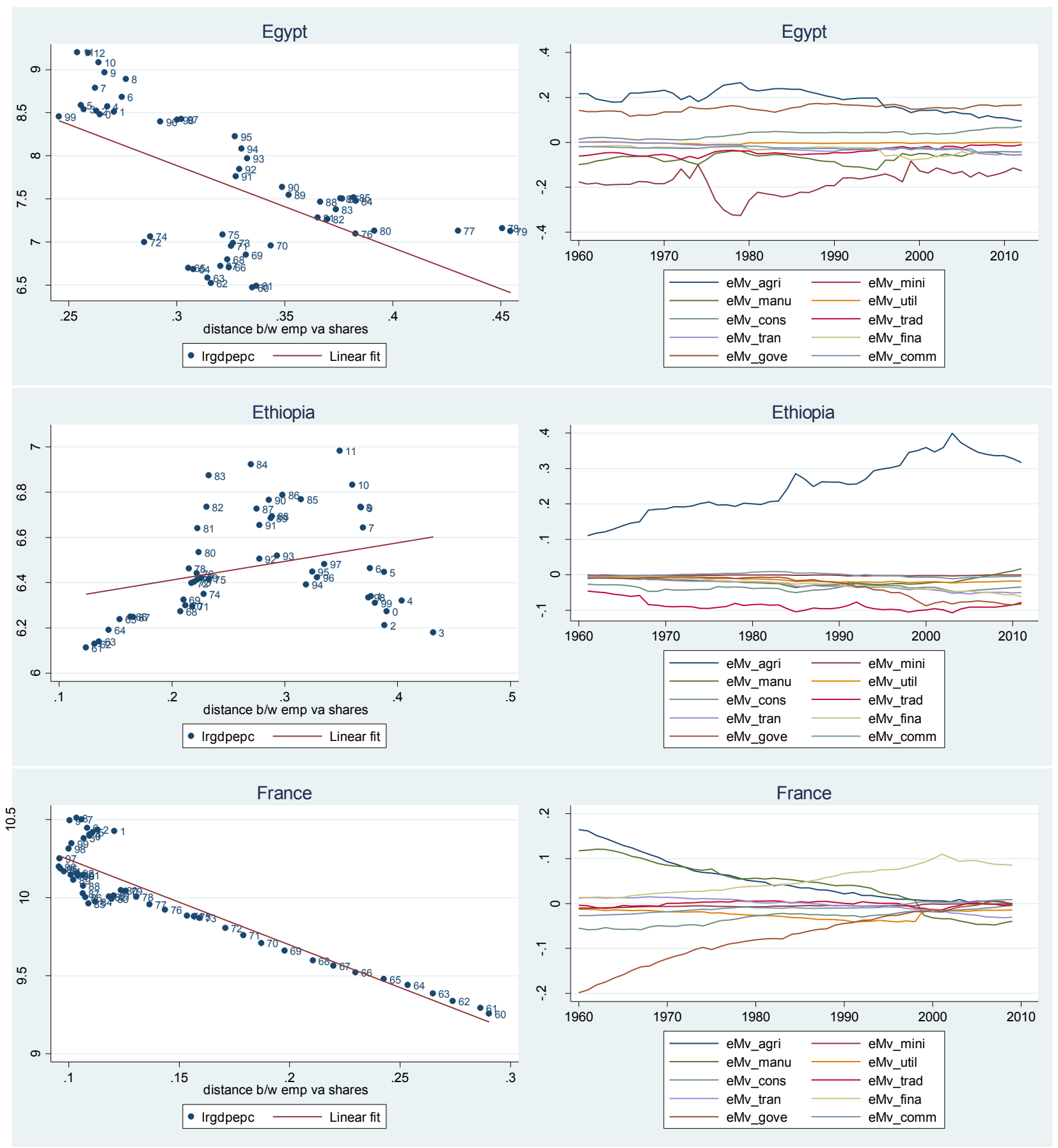



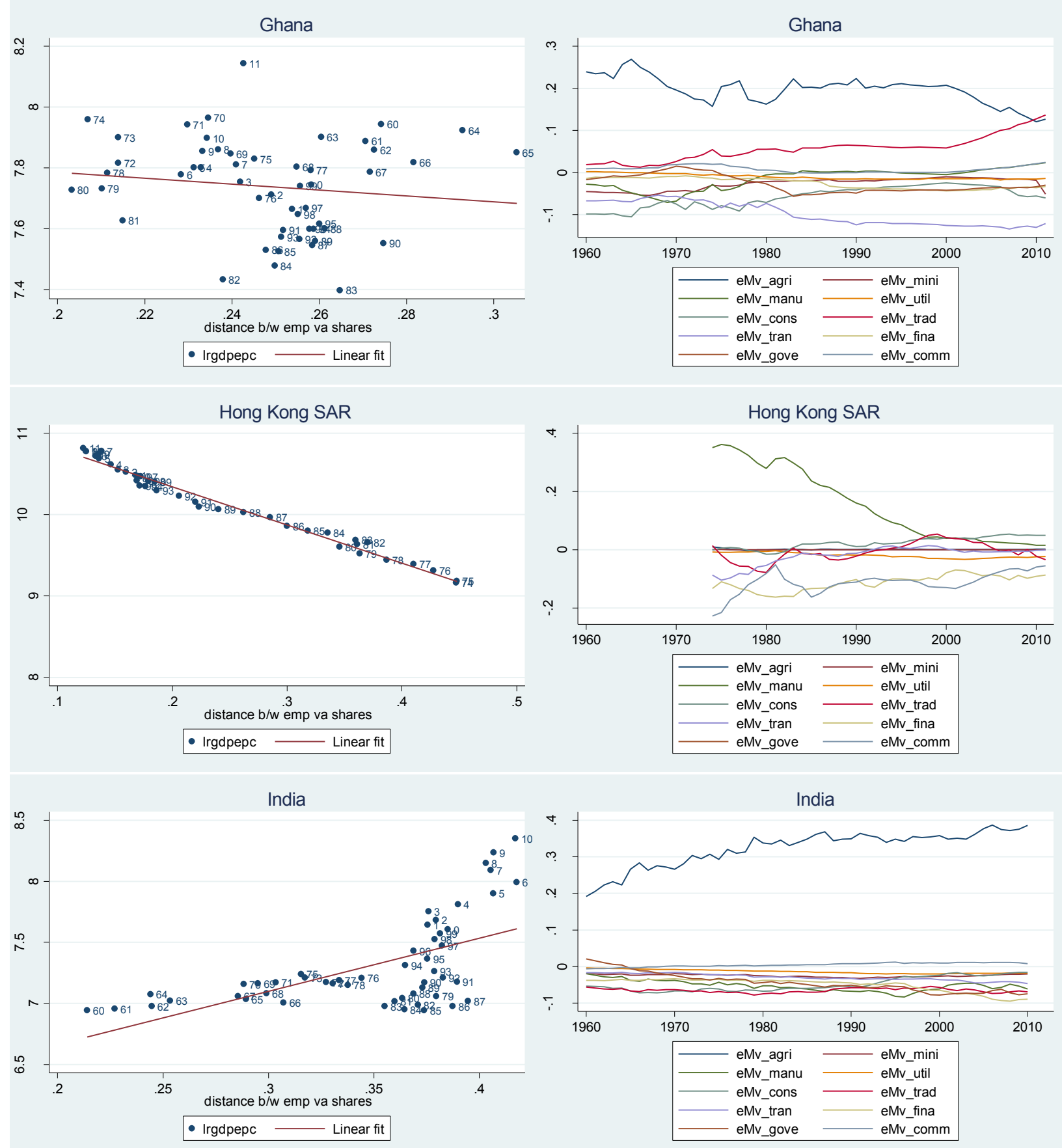

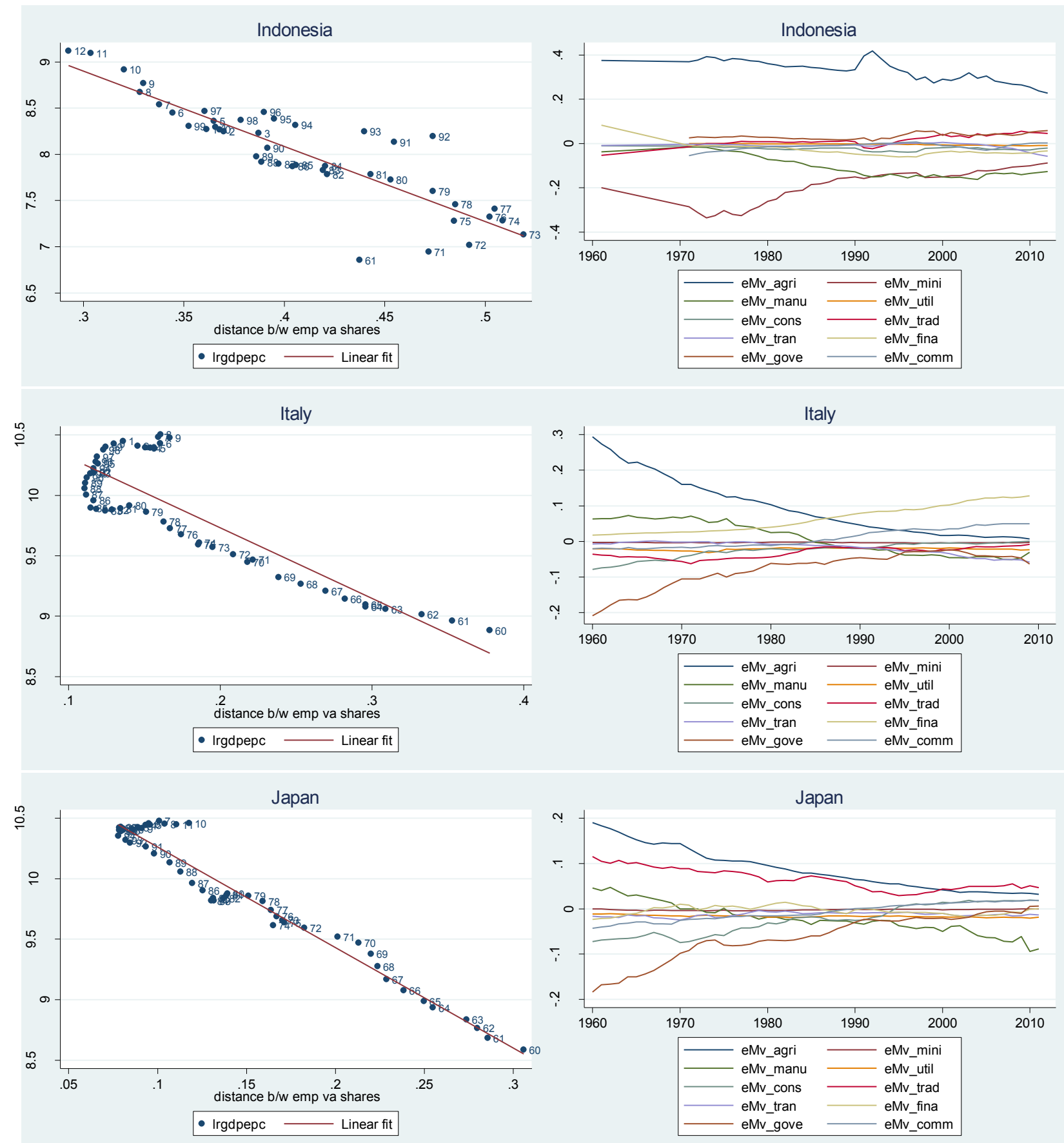

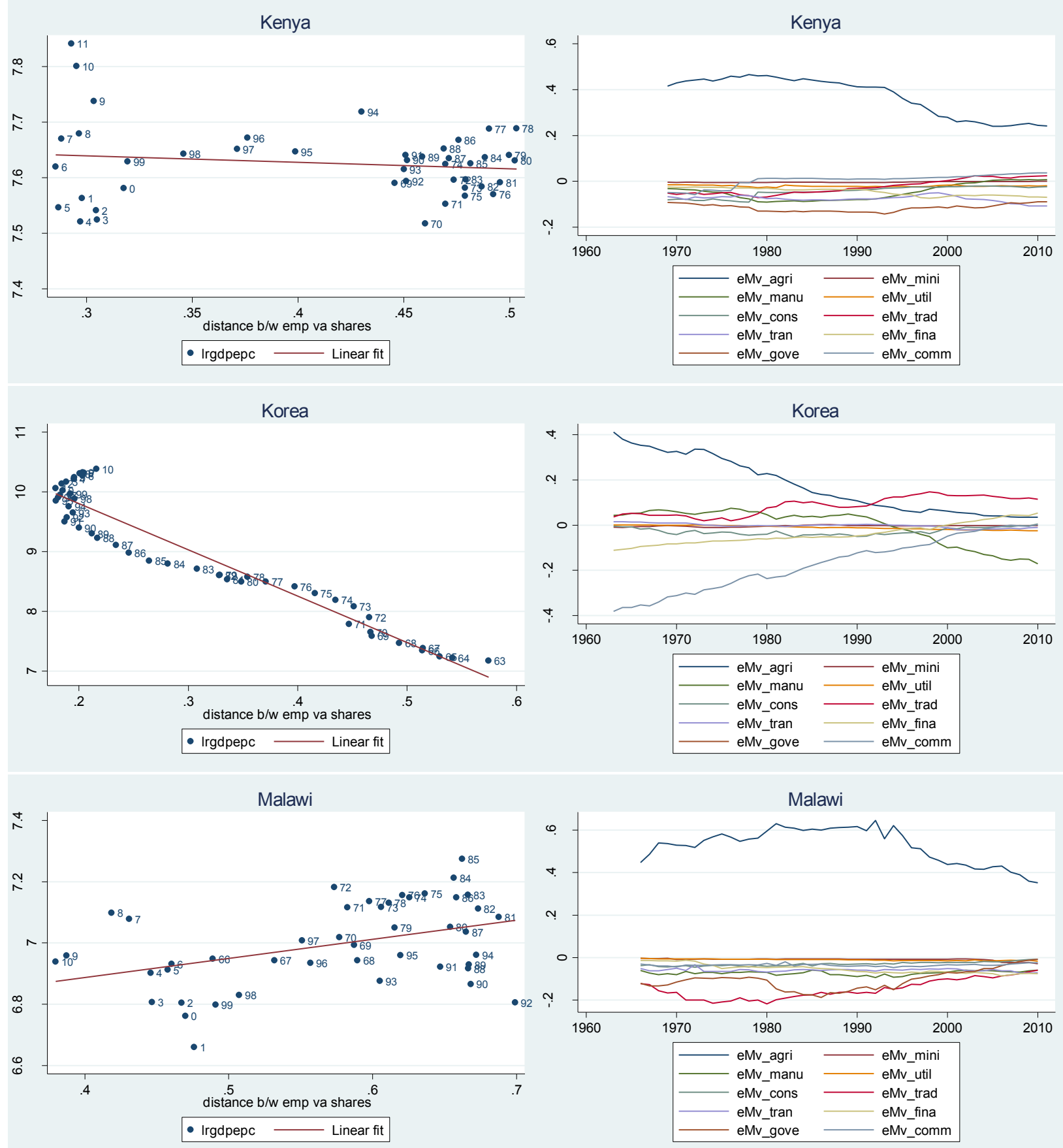

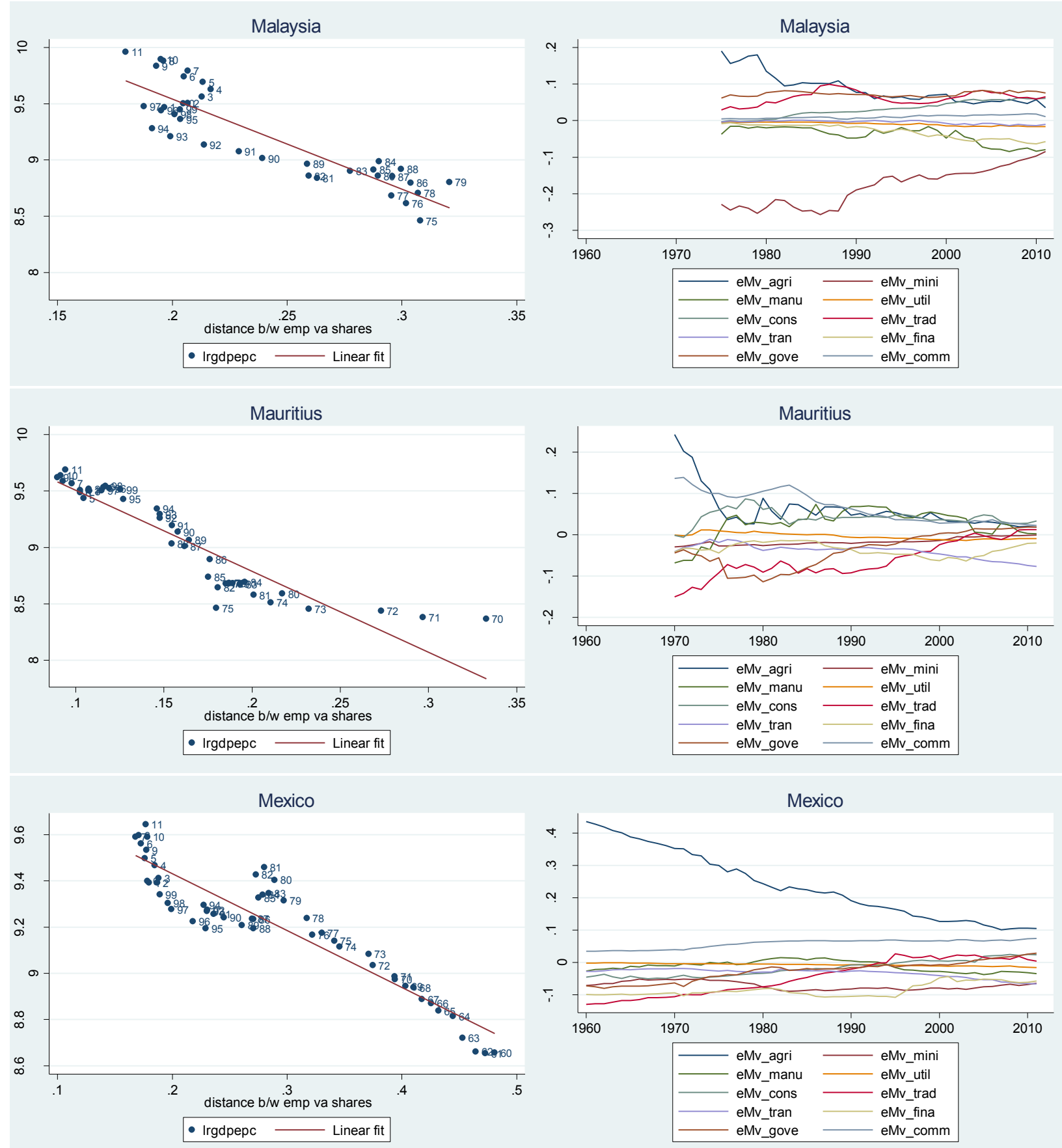

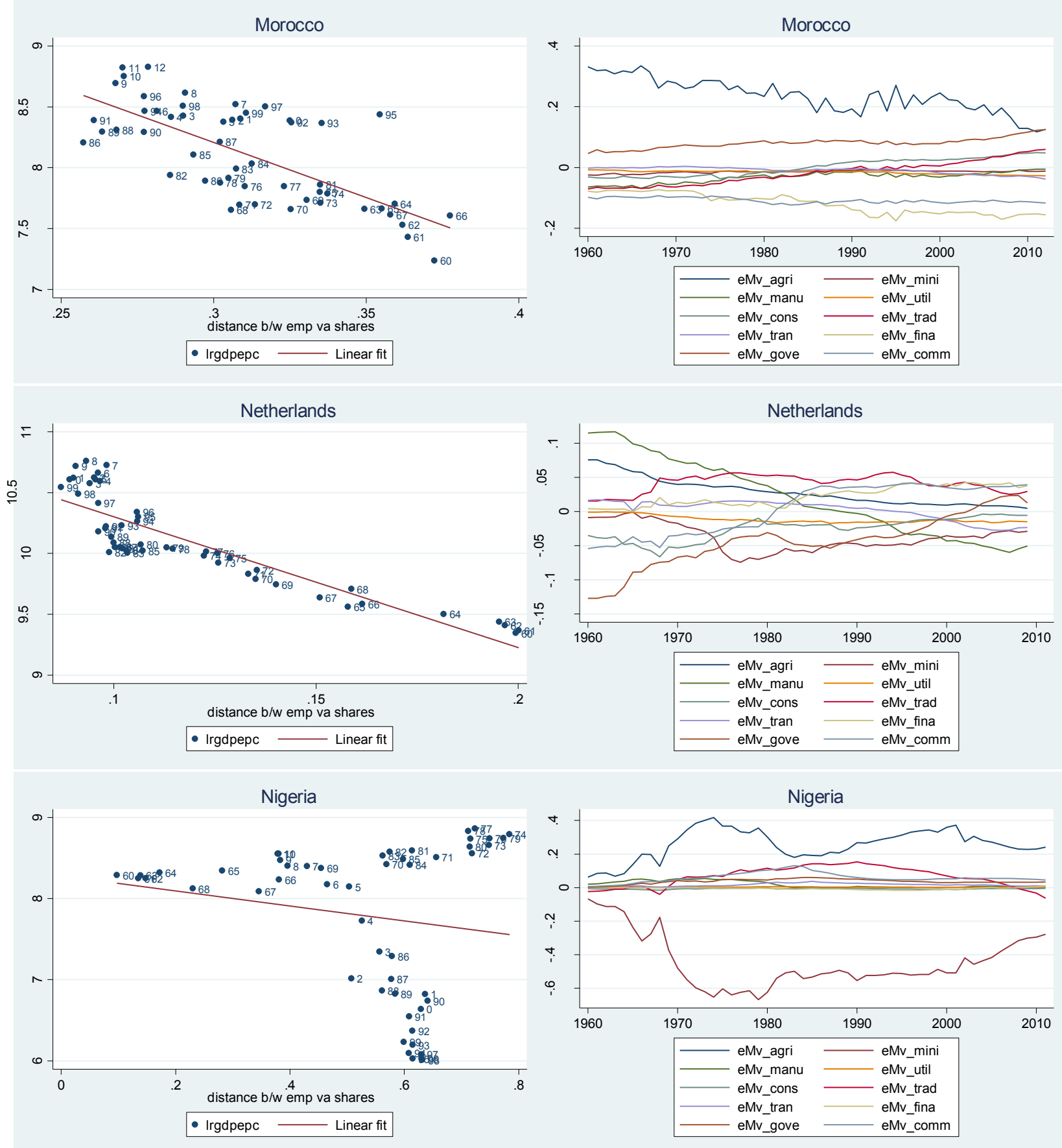

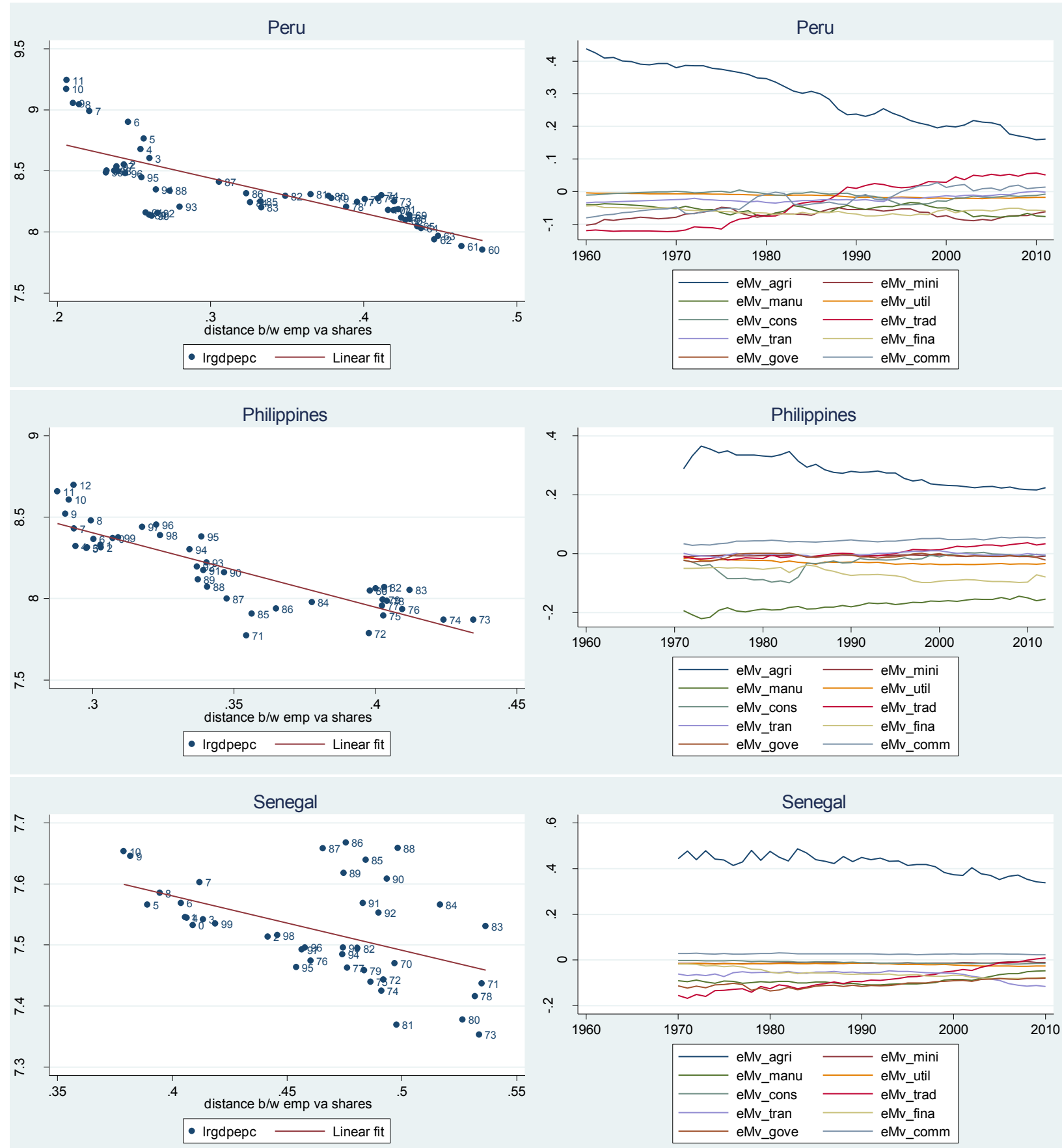

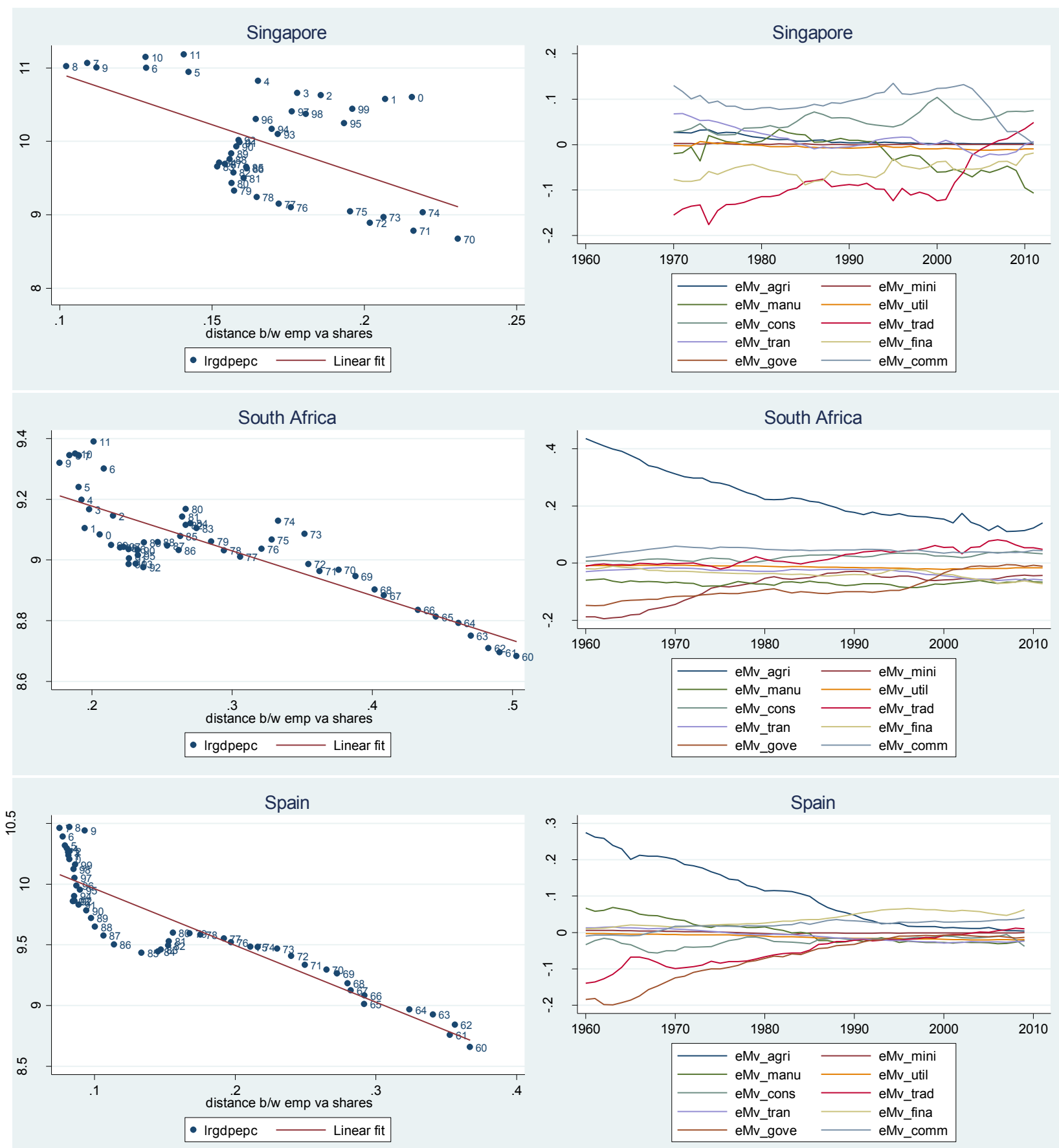

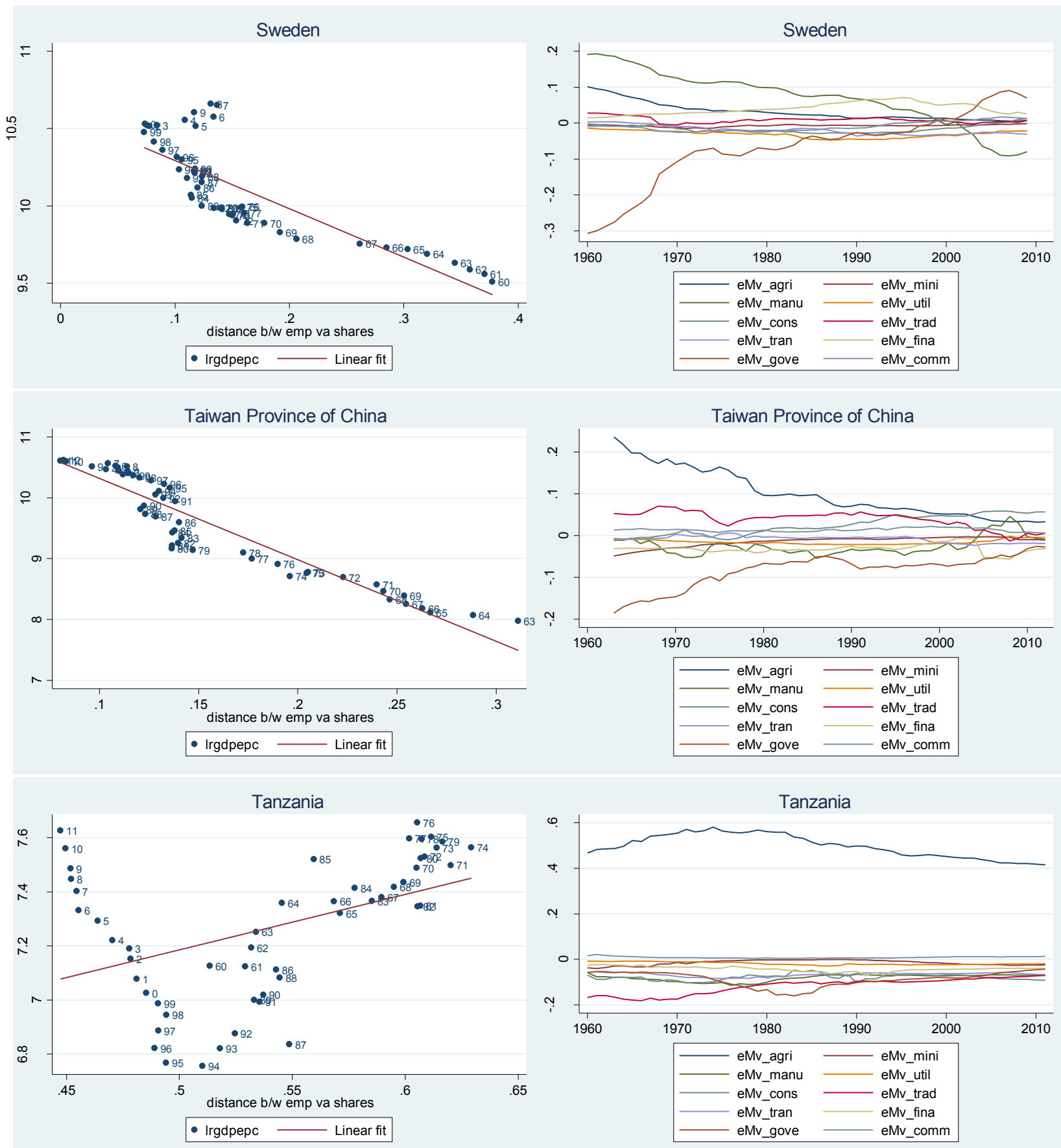

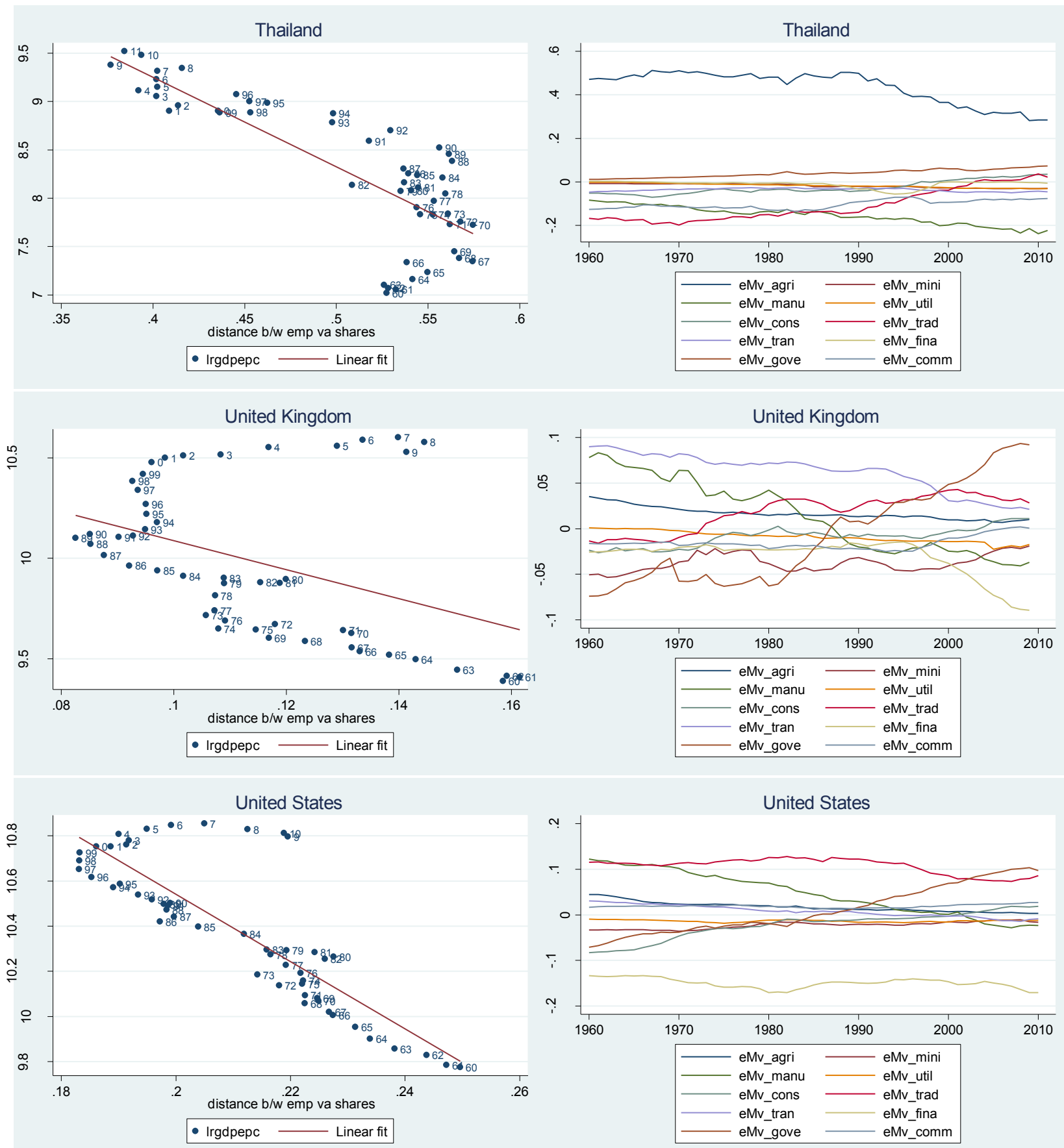

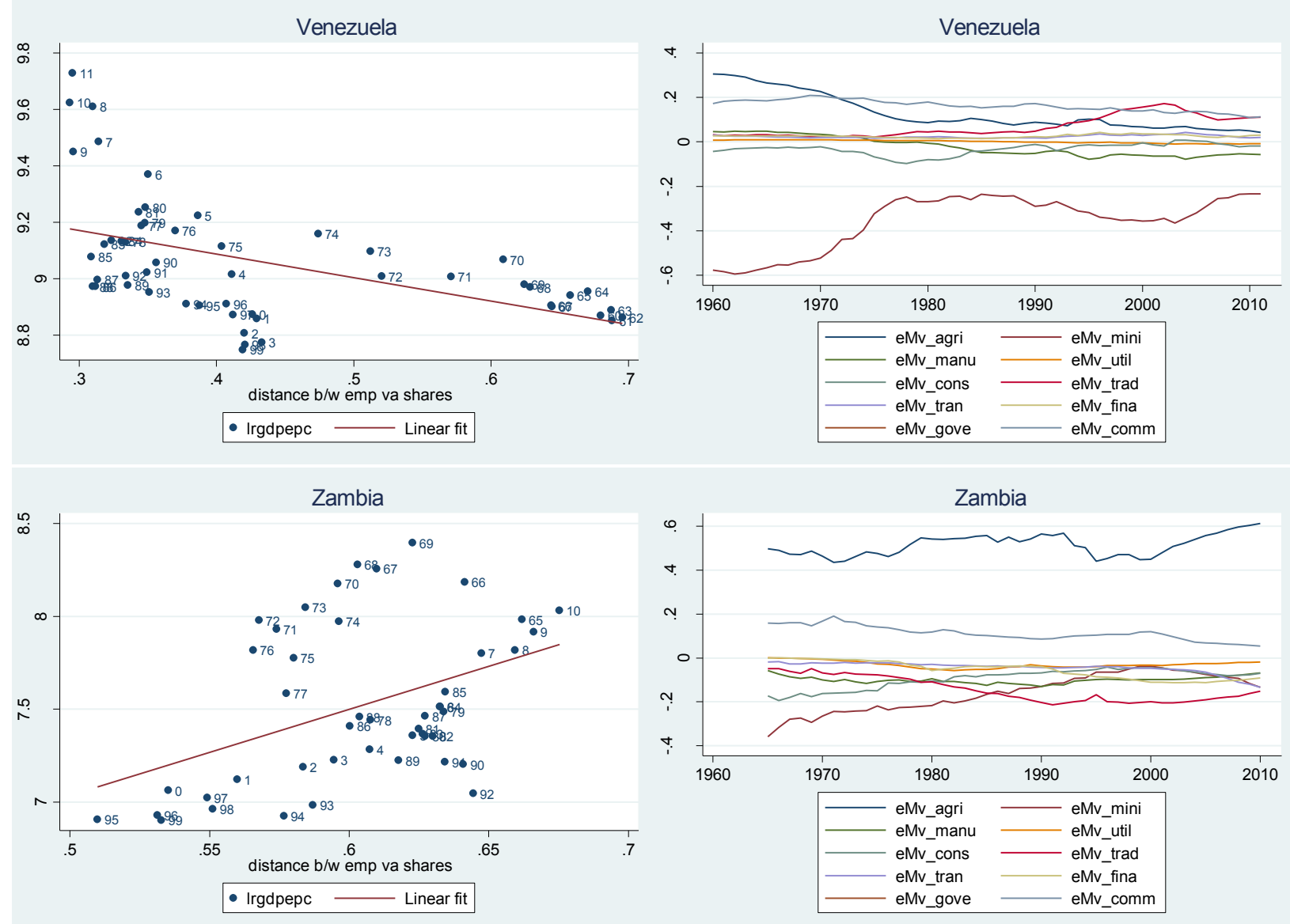